\title{
Challenges and opportunities in improving left ventricular remodelling and clinical outcome following surgical and trans-catheter aortic valve replacement
}

\author{
Xu Yu Jin $(\bowtie)^{1,2}$, Mario Petrou ${ }^{3,4}$, Jiang Ting $\mathrm{Hu}^{2}$, Ed D Nicol ${ }^{4,6}$, John R Pepper ${ }^{3,4,5}$ \\ ${ }^{1}$ Surgical Echo-Cardiology Services, Oxford Heart Centre, John Radcliffe Hospital, Oxford University Hospitals NHS Foundation Trust, \\ Oxford OX3 9DU, UK; ${ }^{2}$ Cardiac Surgical Physiology and Genomics Group, Nuffield Division of Clinical Laboratory Sciences, Radcliffe \\ Department of Medicine, University of Oxford, Oxford OX3 9DU, UK, ${ }^{3}$ Department of Cardiac Surgery, Royal Brompton Hospital, London \\ SW3 6NP, UK; ${ }^{4}$ National Heart and Lung Institute, Imperial College London, London SW3 6LY, UK; ${ }^{5}$ NIHR Imperial Biomedical Research \\ Centre, London W2 1NY, UK; ${ }^{6}$ Department of Cardiology, Royal Brompton Hospital, London SW3 6NP, UK
}

(C) The Author(s) 2021. This article is published with open access at link.springer.com and journal.hep.com.cn

\begin{abstract}
Over the last half century, surgical aortic valve replacement (SAVR) has evolved to offer a durable and efficient valve haemodynamically, with low procedural complications that allows favourable remodelling of left ventricular (LV) structure and function. The latter has become more challenging among elderly patients, particularly following trans-catheter aortic valve implantation (TAVI). Precise understanding of myocardial adaptation to pressure and volume overloading and its responses to valve surgery requires comprehensive assessments from aortic valve energy loss, valvular-vascular impedance to myocardial activation, force-velocity relationship, and myocardial strain. LV hypertrophy and myocardial fibrosis remains as the structural and morphological focus in this endeavour. Early intervention in asymptomatic aortic stenosis or regurgitation along with individualised management of hypertension and atrial fibrillation is likely to improve patient outcome. Physiological pacing via the His-Purkinje system for conduction abnormalities, further reduction in para-valvular aortic regurgitation along with therapy of angiotensin receptor blockade will improve patient outcome by facilitating hypertrophy regression, $\mathrm{LV}$ coordinate contraction, and global vascular function. TAVI leaflet thromboses require anticoagulation while impaired access to coronary ostia risks future TAVI-in-TAVI or coronary interventions. Until comparable long-term durability and the resolution of TAVI related complications become available, SAVR remains the first choice for lower risk younger patients.
\end{abstract}

Keywords surgical aortic valve replacement; trans-catheter aortic valve implantation; left ventricular hypertrophy and fibrosis; myocardial force-velocity relationship; His-Purkinje pacing; renin-angiotensin system inhibitors; coronary access impairment

\section{Introduction}

Aortic valve disease causes obstruction to left ventricular ejection during systole and/or of regurgitation during diastole. These apparently simple mechanical abnormalities lead to profound disturbances of left ventricular physiology, such as progressive myocardial disease and consequent morbidity and mortality. The clinical solution is usually surgical aortic valve replacement (SAVR), occasionally repair, or more recently trans-catheter aortic

Received October 17, 2020; accepted February 20, 2021

Correspondence: Xu Yu Jin, xy.jin@ouh.nhs.uk valve implantation (TAVI). Aortic valve replacement results in a series of adaptive changes in the left ventricular structure and function through a complex biological process which depends on many clinical factors. These include the nature and extent of valve pathology and related myocardial disease, myocardial ischemia/reperfusion injury, changes in ventricular loading, hemodynamic features of the valve substitute, paravalvular aortic regurgitation, ventricular activation abnormalities, and co-morbidities such as hypertension, atrial fibrillation $(\mathrm{AF})$, and coronary artery disease.

The knowledge and practice in this field is continuously evolving and has helped reduce post-operative morbidity and mitigate the long-term risks, particularly in young 
patients, whose survival remains well below the agematched population [1]. Improved left ventricular (LV) function and regression of hypertrophy have traditionally served as intermediate clinical endpoints when novel aortic valve interventions are introduced. More recently, they offer important prognostic value in large-scale randomized trials of TAVI and SAVR patients, thus guiding clinical practice, and facilitating better timing of intervention in asymptomatic patients.

\section{Hemodynamic response to SAVR}

By the end of the 1970s it was established that by relieving aortic stenosis (AS) left ventricular systolic pressure and stroke work both fell, while stroke volume, cardiac index and systemic arterial pressure usually increased, particularly when their preoperative values were low. After correcting aortic regurgitation (AR) there is a fall in LV stroke volume and an increase in diastolic systemic arterial pressure. The forward systemic arterial flow remains unchanged. Over the long-term, exercise capacity increased significantly compared to pre-operative levels. Despite much improvement in operative technique, the impact of myocardial protection and valve substitutes remain fundamental in today's SAVR and TAVI practice. More recently a small LV stroke volume index (SVI) before surgery has been identified as an important marker of adverse long-term prognosis for severe aortic stenosis [2] emphasizing the importance of basic hemodynamic.

\section{Left ventricular force-velocity relationship and incoordination in SAVR}

The early adaptation of LV function in response to relief of aortic stenosis is attributed to a fall in ventricular afterload [3]. Following successful SAVR there is a consistent fall in systolic wall stress and a corresponding increase in the velocity of myocardial fiber shortening. With correction of $\mathrm{AR}$, the large stroke volume associated with AR is reduced but the fall in systolic wall stress and the increase in the velocity of shortening are inconsistent [4]. Significant incoordination of LV contraction may persist, and this may adversely affect outcome. Impaired myocardial contraction was implicated as a cause of adverse patient outcome in a sub-group of patients whose pre-operative force-velocity relationship was already depressed. Recovery of systolic function after correction of AR appears to take longer and be less complete than with AS and thus its presence preoperatively may predict a worse outcome. These early studies have formed the physiologic basis for timing of AVR in AR, along with clinical symptoms, and - in the current international guidelines - by using $45 \mathrm{~mm}$ endsystolic dimension and left ventricular ejection fraction (LVEF) of $\leqslant 50 \%$ as the cut-off point for intervention.
Clinical physiology, based on the force-velocity relationship, provides an important framework in the assessment of myocardial contraction after SAVR, but it also has limitations particularly when changes in loading conditions occur along with ventricular incoordination. Using a combination of intraventricular pressure measurements and ventricular dimensions, obtained by transesophageal echocardiography, pressure-dimension loops are reconstructed. The area within the loop represents the external work done on the circulation by the regional myocardium. As in other forms of ventricular disease, a disturbed pressure-dimension loop occurs most commonly as the result of changes in ventricular cavity shape during two isovolumic periods, thus leading to incoordination and energy loss. This disturbance is common in patients with aortic valve disease, especially pre-operatively (Fig. 1). The pressure-dimension loop assumes a normal shape within a few hours after SAVR suggesting it is either directly or indirectly aggravated by the valve disorder itself and the disturbances of ventricular activation, particularly loss of the septal q wave and an increase in the QRS duration. The presence of incoordination not only has effects on myocardial function but also has a major influence on the interpretation of measurements commonly used to assess it. When the rate of rise of ventricular pressure (peak $+\mathrm{dP} / \mathrm{dt}$ ) is used to assess LV inotropic state, it has been demonstrated that it is significantly affected by incoordination [5]. The timing of events in the cardiac cycle is critical and intraventricular incoordination disturbs this. This is consistent with the findings of Carl Wiggers nearly 100 years ago, who demonstrated that the rate of rise of $\mathrm{LV}$ systolic pressure is equal to the summation of its muscle contraction. Thus, the classical approach to assess the forcevelocity relationship in the intact ventricle, by plotting wall stress against shortening velocity, is valid only in the absence of significant incoordination. When the timing of events in the cycle of ventricular contraction and relaxation is correct, a low shortening rate reflects the presence of high wall stress (Fig. 2A). When significant incoordination is present, peak shortening velocity relates directly to the degree of incoordination (Fig. 2B). Two decades on, these classical physiologic frameworks remain instrumental in large-scale echocardiography studies, and are further extended into predicting myocardial fibrosis and clinical prognosis of AS patients. Ito et al. [6] studied LV end systolic stress-strain relationship of 101 AS patients with myocardial biopsy during SAVR. They demonstrated that a significant downward shift of the stress-strain slope in AS patients, in comparison with normal control group, was modestly correlated with the degree of interstitial myocardial fibrosis, thus in keeping with an advanced stage of myocardial disease independent from the raised afterload. Prihadi et al. [7] studied mechanical dispersion measured by the time dispersion of peak systolic LV longitudinal global strain (LGS) using speckle tracking 
A

LV pressure $(\mathrm{mmHg})$

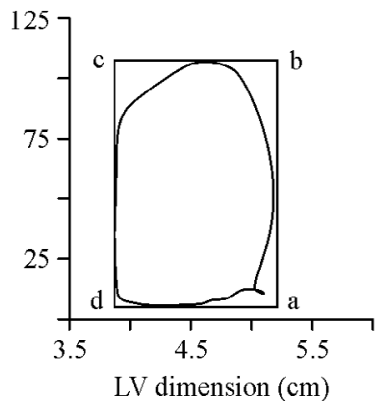

B

Pressure $(\mathrm{mmHg})$

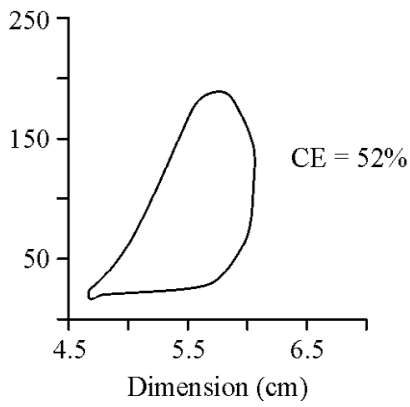

$\mathrm{C}$ After AVR (20 hours) Pressure $(\mathrm{mmHg})$

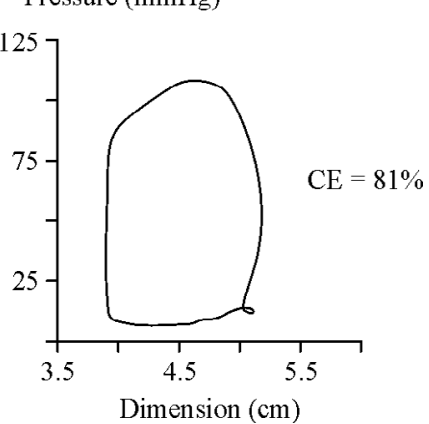

Fig. 1 (A) Left ventricular (LV) pressure-dimension loop constructed from simultaneous recordings of left ventricular cavity pressure and circumferential dimension. The loop area represents the external work done on the circulation by the segment studied. The area of the rectangle ( $\mathrm{a}, \mathrm{b}, \mathrm{c}$, and $\mathrm{d}$ ) that just encloses the loop represents the maximal possible work that could have been done by the ventricle over the same range of pressure and dimension. Cycle efficiency is defined as the ratio of loop area to that of the rectangle and reflects the efficiency of energy transfer. Loop (B), a typical example of the change in cycle efficiency (CE) before, and loop (C), $20 \mathrm{~h} \mathrm{after}$ aortic valve replacement (AVR) from a patient with aortic stenosis. The lower cycle efficiency before AVR (52\%) was due to abnormal dimension lengthening during isovolumic contraction and dimension shortening during isovolumic relaxation. These abnormalities are no longer present $20 \mathrm{~h}$ after AVR, and cycle efficiency has increased to 81\%. Reprinted with permission from Jin et al., Am J Cardiol, 1994; 74: $1142-1146$.
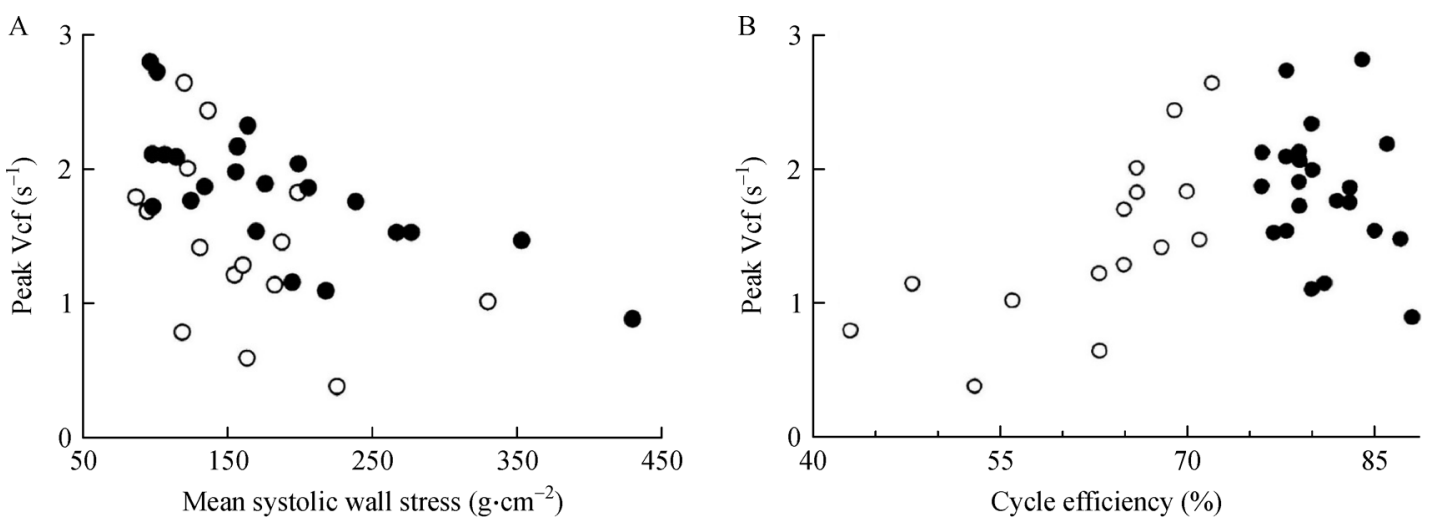

Fig. 2 (A) Peak velocity of circumferential fiber shortening (peak Vcf) plotted against mean left ventricular (LV) systolic circumferential wall stress, before relief of aortic stenosis. Note that there is an inverse significant linear correlation between the two in coordinate ventricles (closed circles, $r=-0.71, P<0.01$ ) but not in incoordinate ones (open circles, $r=-0.45, P>0.05$ ). Demonstrating the importance of coordination in order to preserve the force-velocity relationship. (B) Peak Vcf plotted against LV cycle efficiency, before relief of aortic stenosis. Note that there is no significant correlation between the two in coordinate ventricles (closed circles, $r=-0.27$, $P>0.05)$ but in incoordinate ventricles (open circles) peak Vcf correlated positively $(r=-0.65, P<0.02)$ with cycle efficiency. Reprinted with permission from Jin et al., Heart, 1996; 76: 495-501.

echocardiography in 630 AS patients. The mechanical dispersion increased from mild/moderate AS to severe AS groups and provided an incremental prognostic value to allcause mortality during 107-month follow-up. Slimani et al. [8] from Mayo Clinic recently studied 445 AS patients regarding the prognostic value of LVEF-mid wall systolic stress relationship. Those who fell below the 95\% confidence interval of the slope had worse clinical survival despite of an LVEF $>60 \%$ and aortic valve effective orifice area $(E O A)>1.0 \mathrm{~cm}^{2}$. The advantage of noninvasive imaging and estimation of systolic wall stress has enabled the clinicians to study large numbers of AS patients with long-term follow-up. One should, however, also acknowledge significant methodological limitations as pointed out by Reichek in his editorials [9]. His comments are especially relevant regarding the accuracy of noninvasive measurement of end-systolic wall stress. Further technical innovations are required. 


\section{Left ventricular diastolic dysfunction in AS and after SAVR or TAVI}

Left ventricular diastolic dysfunction has long been recognized in aortic stenosis along with LV hypertrophy. The characteristic patterns of dimensional changes and wall thinning during isovolumic relaxation and early diastolic filling were well established in the 1970s based on M-mode echocardiography. In the 1980s, trans-mitral flow velocity was used to assess global diastolic filling patterns. The interpretation of these Doppler measurements depends on the relationship of the phasic pressure difference between left atrium and left ventricle. In isolated aortic stenosis, it was noted that patients with a normal ejection fraction and normal pulmonary capillary wedge pressure also had a normal rate of isovolumic left ventricular pressure decay, although filling occurred primarily during atrial systole. In contrast, in patients with systolic dysfunction and elevated mean pulmonary capillary wedge pressure, isovolumic pressure decay of left ventricle was prolonged, while filling occurred mainly during early diastole, with a reduced atrial contribution and a shortened isovolumic relaxation period. The single most important predictor of the trans-mitral filling pattern was therefore the pulmonary capillary wedge pressure, while the left ventricular mass was the most powerful predictor of the rate of left ventricular pressure fall. Peak filling rate alone was not helpful in detecting diastolic dysfunction in patients with aortic valve disease. A series of invasive studies demonstrated that left ventricular relaxation, filling, and end diastolic stiffness were all disturbed by LV hypertrophy due to aortic stenosis [10]. Non-invasively, pulmonary venous flow pattern and tissue Doppler velocity of mitral annulus motion, when combined with mitral valve $\mathrm{E}$ wave velocity, provides a more useful estimation of pulmonary wedge pressure and the degree of LV diastolic dysfunction. This has gained wide clinical acceptance and is routinely captured in echocardiography guidelines and individual reports. In recent years, speckletracking echocardiography has provided more robust regional myocardial deformation data. Of particular importance is the LGS as a sensitive early marker of LV impairment in contraction and relaxation. Recently, Thaden et al. [11] reported the prognostic implication of diastolic function in 1383 consecutive AS patients with normal LVEF who underwent AVR at the Mayo Clinic, of which $43 \%$ of patients with significantly increased LV filling pressure had an adjusted HR 1.45 of death during 7 years follow-up when compared with those with normal filling pressure. Ong et al. [12] also studied the implication of LV diastolic dysfunction on outcome in $1750 \mathrm{AS}$ patients prior to TAVI. Using MV E/A ratio cut-off at 0.8 and 2.0, patients were graded into I, II, and III of diastolic dysfunction. Incremental baseline grade was associated with an increased 2-year all-cause mortality, cardiovascu- lar death, and re-hospitalisation. The improvement in one grade at 30 days after TAVI was associated with reduced cardiovascular death at 1 year.

In contrast to extensive reports on pre- and postoperative assessment of LV diastolic function in SAVR or TAVI patients, the very acute changes in myocardial diastolic function during SAVR also provide important insight. Our group used peri-operative transesophageal echocardiography and demonstrated that the reduction in early diastolic lengthening rate of the transverse left ventricular dimension, and a reduction in posterior wall thinning rate did not improve immediately after SAVR for aortic stenosis. It only occurred $12-24 \mathrm{~h}$ later in a time course similar to that of the regression of incoordination and increase in stroke volume [3]. The increase in the duration of diastole, secondary to the shortening of systole, is likely to have had physiologic advantages in increasing the time available for ventricular filling and coronary flow after operation.

Regression of hypertrophy after SAVR accounts for the long-term improvement in diastolic function, along with longitudinal LV contraction. However, the relative increase in interstitial fibrosis early after SAVR (when the myocyte hypertrophy has significantly regressed) was associated with elevated chamber stiffness, which took longer to regress than changes in the myocytes. Indeed, the normalization of LV diastolic function and non-uniformity can take up to 5 years to establish. For AR patients, LV diastolic dysfunction remains up to 7 years after SAVR [13]. In today's practice, the age of SAVR and TAVI patients is continuously rising with more LV myocardial fibrosis. As such, the remodelling of LV diastolic function after surgery is often less satisfactory. The incidence of moderate to severe diastolic dysfunction can actually increase after SAVR partly due to lack of LV geometry remodelling and a relative increase in myocardial stiffness. Pre-op LA dilatation and diastolic dysfunction is another marker that is positively related with the degree of LVH and predicts worse long-term outcome [14].

\section{Effects of prosthetic valve hemodynamics on the regression of LVH}

Significant residual pressure gradient across aortic valve prostheses after SAVR and its non-physiologic flow profiles result in adverse long-term clinical outcome, especially in those patients with a small annular orifice (21 mm diameter or less) and prior impaired LV systolic function. In fact, prosthesis-related LV pressure increase has been demonstrated to cause incomplete regression of ventricular and cellular hypertrophy as well as increased interstitial fibrosis [15]. Prosthesis-patient mismatch (PPM) not only increases early postoperative mortality, but also has a worse mid-term patient outcome and 
incomplete LVH regression. The latest long-term followup of large case series concluded that a significant residual gradient due to severe PPM defined as an EOA index less than $0.65 \mathrm{~cm}^{2} / \mathrm{m}^{2}$ does lead to an adverse prognosis $[16,17]$. Of note, patients who have impaired baseline LV function and co-existing coronary artery disease are the most vulnerable group that suffers from the adverse effects of PPM after SAVR. To reduce the incidence of PPM in stented or mechanical AVR, clinical interest in stentless AVR was re-introduced in the 1990s. At a given valve size, the removal of a stent improved prosthesis cross-sectional area for aortic flow and allowed annulus dynamics to be partially preserved, thus offered flow-related increase in EOA [18]. The in-vivo hemodynamic performance of stentless AVR has lived up to these expectations and outperformed stented bioprostheses thus has contributed to post-operative ventricular remodelling. Indeed, the ability of the patient to exercise after a stentless valve implant was enhanced compared to stented valve substitutes. In the past 10 years, stentless AVR has been less frequently used due to its surgical complexity in implantation as well as the hemodynamic improvement in new stented aortic bioprostheses. Nevertheless, from a historical point of view, the renaissance of stentless AVR in the 1990s provided the intellectual and technical basis for subsequent development of sutureless AVR and trans-catheter TAVI devices. For example, the clinical success of ATS 3F stentless AVR [19] that was designed with unique tubular aortic cusps using equine pericardium has laid down the cornerstone for the first generation TAVI device. In addition, our surgical echo research in aortic root geometry and stentless valve competence [20] has not only guided surgical case selection and stentless valve sizing but also contributed to the design of next generation valve prostheses, evidenced by the frequent citations by patent applications according to Google Scholar.

The systolic pressure gradient and EOA of a TAVI device is largely comparable to that of SAVR. The incidence of moderate to severe PPM in TAVI is slightly lower than in SAVR particular in those with self-expansion and super annular position. However, to extrapolate the prognostic value of PPM from SAVR to TAVI patients is not a straightforward undertaking. The clinical impact of PPM was established in SAVR with patients under 75 years old, where the risk model of comorbidity is different from those of TAVI patients with 10 years older. The TAVI group also has different competing risk factors of mortality. Meta-analysis reported by Liao et al. [21] showed a 36\% incidence of moderate to severe PPM among 4691 TAVI cases but did not find a significant impact on 30 days or 2 years survival. As was acknowledged by the authors, the clinical interpretation of these findings in TAVI should be treated with caution given the age, baseline valve gradient, follow-up time and other competing risk factors for early mortality, notably the para-valvular AR, MR, conduction abnormality and heart failure. Indeed, Pibarot et al. [22] reported from the Partner-IA trial and found a similar result in the randomized arm. But after excluding the patients with significant para-valvular AR, the adverse impact of severe PPM on medium term survival after TAVI was demonstrated with HR 1.88. During a 4-year follow-up, Poulin et al. [23] reported that $40 \%$ of TAVI cases had PPM, which was associated with impaired recovery in LV systolic longitudinal strain (LGS), although its impact on patient survival was not apparent. This may be explained by the report from Ngo et al. [24], which randomized 232 cases to TAVI or SAVR. Despite a greater EOA with the Core valve versus SAVR $(1.02 \pm 0.05$ vs. $\left.0.65 \pm 0.04, \mathrm{~cm}^{2} / \mathrm{m}^{2}, P<0.001\right)$, its 1 -year $\mathrm{LV}$ mass index regression was much less than that after SAVR $(7.3 \% \pm 2.8 \%$ vs. $21.5 \% \pm 2.7 \%, P<0.001)$. This was underlined by an increase in LV end diastolic volume after TAVI due to a higher incidence of para-valvular AR and pacemaker implantation, illustrating a more complex LV remodelling after TAVI.

The rationale for achieving an efficient hemodynamic performance of an aortic prosthesis is to facilitate ventricular remodelling and hypertrophy regression. Such a notion seemed less appreciated in the first three decades of SAVR when the focus was more on improving valve thrombogenesis and durability. Our early research in the 1990s regarding ventricular remodelling after SAVR using aortic homografts or stentless bioprostheses demonstrated a more rapid and complete regression of LVH than with stented AVR [25]. We proposed to consider LVH regression as one of the hallmarks in defining the efficacy of SAVR. Further meta-analysis by Kunadian et al. [26] confirmed that stentless AVR did provide an advantage in $\mathrm{LVH}$ regression in the first 6 months by providing a greater orifice area and a lower gradient. Commenting on these data, we further highlighted that a significant baseline LVH was required in order to demonstrate the advantage of a lower aortic prosthesis pressure gradient to LVH regression after SAVR [27,28]. Nevertheless, incomplete LVH regression still occurs in nearly half of contemporary SAVR and is an indicator of adverse clinical outcome thus arguing for earlier SAVR [29]. After uncomplicated TAVI, LVH regression shared a similar pattern to that after SAVR but was also affected by para-valvular AR and permanent pacemaker implantation, which will be discussed in later sections. Echo and clinical outcome data from large-scale prospective TAVI trials and registries have provided more robust insights that not only reiterate what we have learned from the SAVR, but also demonstrated the prognostic value of baseline LVH and its regression. Gonzales et al. reported the Partner trial with 4280 TAVI cases for AS and demonstrated that the group of patients with severe baseline LVH has a HR of 1.34 for 5-year CV death, rehospitalization versus those who had no baseline LVH [30] (Fig. 3). In addition, Chau et al. also reported the 


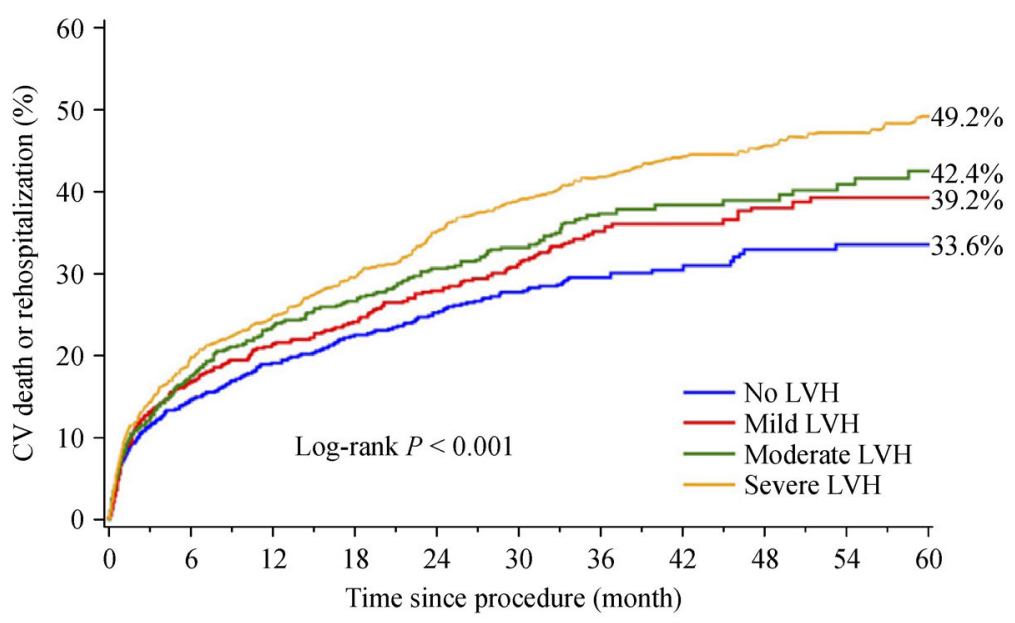

\begin{tabular}{lccccccccccc}
\multicolumn{2}{l}{ Number at risk: } & & & & & & & & & \\
No LVH & 1325 & 1089 & 997 & 938 & 871 & 597 & 545 & 144 & 129 & 112 & 66 \\
Mild LVH & 777 & 632 & 581 & 544 & 501 & 346 & 302 & 135 & 118 & 99 & 57 \\
Moderate LVH & 628 & 497 & 448 & 417 & 387 & 265 & 232 & 112 & 103 & 84 & 51 \\
Severe LVH & 1550 & 1196 & 1086 & 991 & 890 & 664 & 590 & 344 & 300 & 262 & 139
\end{tabular}

Fig. 3 Event rates are shown over 5 years after TAVR according to baseline severity of LVH (sex-specific categories of no, mild, moderate, or severe $\mathrm{LVH}$ ) for the composite of $\mathrm{CV}$ death or rehospitalization. $\mathrm{CV}$, cardiovascular; $\mathrm{LVH}$, left ventricular hypertrophy; TAVR, transcatheter aortic valve replacement. Modified with permission from Gonzales et al., JACC Cardiovasc Interv, 2020; 13(11): $1329-1339$.

significant impact of 1-year LVH regression on 5-year outcome from the Partner trial data sub-study that included 1434 AS patients. The quartile with least regression of LV mass index was associated with adjusted HR 1.71 of allcause mortality at 5 years, when compared with the quartile of greatest LV mass regression [31]. The underlying mechanism of residual LVH is complex and often due to events beyond the valve prosthesis hemodynamic performance itself. Two decades ago we proposed that they basically fell into four categories: (1) secondary to prior aortic valve disease, (2) prosthesis function and operation/ intervention related myocardial injury, (3) secondary to systemic vascular disease, and (4) due to cardiac rhythm and conduction abnormalities [32]. The reports from recent TAVI studies validated the long-advocated notion that LVH should be incorporated into the timing of SAVR and TAVI [25,30-32] as well as in its post procedure medical treatment which will be discussed in later sections.

\section{Effects of TAVI access on LV remodelling and outcome}

Aortic stenosis and LV hypertrophy result in significant reduction in LV global longitudinal systolic strain (GLS), particularly in LV middle to basal segments. LV global systolic and diastolic function is increasingly compensated by enhanced apex contraction and rotation as well as circumferential systolic strain. These mechanisms together with concentrical ventricular geometry have helped to maintain the LVEF within normal range in AS patients [33]. Following SAVR, its physiologic benefits to LV remodelling usually take 3-6 months to emerge while the prior enhanced circumferential systolic strain starts to regress toward normal. In such context, maintaining an active LV apex function is imperative early after SAVR and TAVI [34]. One should, therefore, not be surprised by a detrimental physiologic consequence and adverse prognosis if significant injury was made to LV apex function in TAVI via apex (TA-TAVI). Indeed, the TAVI via TA was consistently shown to have higher early and late mortality and a slower recovery in cardiac function than those via the femoral artery (TF-TAVI) or other non-apical access. Meyer et al. compared LV regional systolic strain using cardiac magnetic resonance image of 20 cases of TA-TAVI versus 24 cases of TF-TAVI for AS. At 3 months followup, the peak systolic longitudinal and radial strains significantly reduced in LV apex segments and the apex cup in the TA-TAVI group, while LV systolic strain in basal and middle segments did not differ [35]. Deng et al. reported using 3D strain echocardiography assessment in 20 AR patients who received TA-TAVI with a 12-month follow-up. There was significant worsening in apex rotation and lack of improvement in global LVEF despite significant reduction in LV volume and mass index [36]. The functional impairment in the LV apex was associated with a greater elevation in cardiac biomarkers and a worse outcome. Ribeiro et al. reported a greater elevation in 
cardiac troponin $\mathrm{T}$ and $\mathrm{CK}-\mathrm{MB}$ in 205 cases of TA-TAVI than those in 45 cases of TAVI via aortic access. These elevations were associated with a lesser improvement in LVEF and GLS at 6-12 months follow-up, and with a higher mortality at 30 days and 1 year [37]. From a multicenter registry of 1131 TAVI cases, Riberio et al. [38] further reported that TA-TAVI had a greater elevation of CK-MB, which was translated into impaired LV systolic function at 6-12 months, and a higher mortality at 30 days, 1 year, and 2 years follow-up. Elmariah et al. [39] further reported the Partner I trial regarding the implication of baseline LV function and TAVI accesses. It included 1027 TF-TAVI and 1057 TA-TAVI. By comparing TF-TAVI with TA-TAVI, the latter had an increased 2-year mortality risk with HR 1.57 when LVEF $<50 \%$, with HR 1.38 when LVEF $>50 \%$. In contrast, for those with LVEF $<50 \%$ but underwent TF-TAVI, there was a great improvement in LVEF and 6 min walk at 30 days follow-up than TA-TAVI. Given that TA-TAVI leads to greater myocardial injury, significantly impaired apex function and worse clinical outcome, this approach is now less frequently used than via femoral artery. In patients with no suitable femoral or other access, TA-TAVI is better considered in patients with LVEF $>50 \%$.

\section{TAVI related para-valvular AR and its impact on LV remodelling and outcome}

In modern cardiac surgery, intra-operative transesophageal echocardiography has become an integral part of the operation. Moderate or severe para-valvular aortic prosthesis regurgitation is diagnosed and rectified in the operating theater in SAVR. Thus, its incidence is below $1 \%$ per patient year in the long term follow-up. The introduction of TAVI has benefitted many high-risk patients who otherwise would be unsuitable for SAVR. Physiologic benefits are evident after uneventful TAVI with LVH regression and functional improvement. Among the complications, moderate or greater para-valvar AR occurred in $10 \%-15 \%$ of patients receiving the first generation of TAVI devices, and had immediate deleterious impact on the ventricular remodelling and early outcomes. Second or third generation TAVI devices have added the external pericardium cloth around the landing zone with a higher skirt to better engage and seal off gaps with the native calcified aortic annulus. This, together with matured implantation experiences, has largely abolished severe para-valvular AR and more than halved the incidence of moderate AR. This was demonstrated by the study using quantitative aortic root angiograms and independent core image laboratory analysis [40]. Based on this multicenter pooled data of 2258 cases across both first and second generations of TAVI devices, Modolo et al. showed that average incidences of moderate to severe paravalvular AR have been reduced to $5 \%$ in second generation TAVI devices, with the Lotus valve being as low as $2.2 \%$ (Fig. 4). UK TAVI registry reported Lotus valve had $0.8 \%$ of moderate to severe paravalvular AR, although with a higher early implantation rate of permanent pacemaker at $32 \%$ [41]. In contrast, with Evolute R valve implantation the incident of moderate to severe paravalvular AR was higher, at $7.8 \%$ while permanent pacing implantation was lower, at $14.7 \%$ [42]. The latest report of a randomized SOLVE-TAVI trial of 447 cases also demonstrated a much lower incidence of moderate to severe paravalvular AR at $1.5 \%$ and $3.4 \%$ following balloon-expansion or selfexpansion TAVI implants, although the rate of permanent pacemaker implants remains relatively high at $19.2 \%$ and 23\% [43]. There appears to be an inverse relationship between the incidence of para-valvular AR and the rate of pacemaker implantation.

In response to significant new $\mathrm{AR}$, the aging left ventricle is less capable of adapting from concentric hypertrophy to a mixed concentric and eccentric hypertrophy. The regulation in myocardial cellular and molecular physiology is complex and not fully elucidated in a clinical setting. Inevitably, significant para-valvular AR causes adverse physiologic consequences such as raised LV end diastolic pressure, reduced coronary perfusion pressure and flow, failure of LVH to regress, thus systolic and diastolic dysfunction, and ultimately hospitalization and worse survival [44]. Mild para-valvular AR following early TAVI implants occurs in 30\%-50\% of cases and was recognized as a significant risk factor for 3-year survival in the original report of the PARTNER trial in 2012 [45] but its clinical importance has attracted less attention. Recent data from the OCEAN-TAVI registry reported by Yoshijima et al. should make us think twice [46]. In comparison with 1026 cases of none or trivial AR after TAVI implant, 546 patients with mild para-valvular AR had a greater risk for hospital readmission for heart failure (HR 1.57), particularly in patients with baseline severe concentric hypertrophy, LVEF below 50\% and prior MR or AR. Further reduction in mild para-valvular AR is very desirable for TAVI patients, provided a low incidence of cardiac conduction abnormalities can be maintained at the same time.

\section{Effects of pacemaker and bundle branch block on LV remodelling and outcome}

The electrical activation sequence of the hypertrophic left ventricle has an important bearing on its remodelling after relieving aortic stenosis. Conventional SAVR has a low permanent pacemaker implant (PPI) within 30 days. Mayo Clinic reported $2.5 \%$ of PPI rate in 5842 SAVR patients with mean surgical age of 74 years old. PPI has, however, an adverse impact on long-term survival with HR 1.49 in 


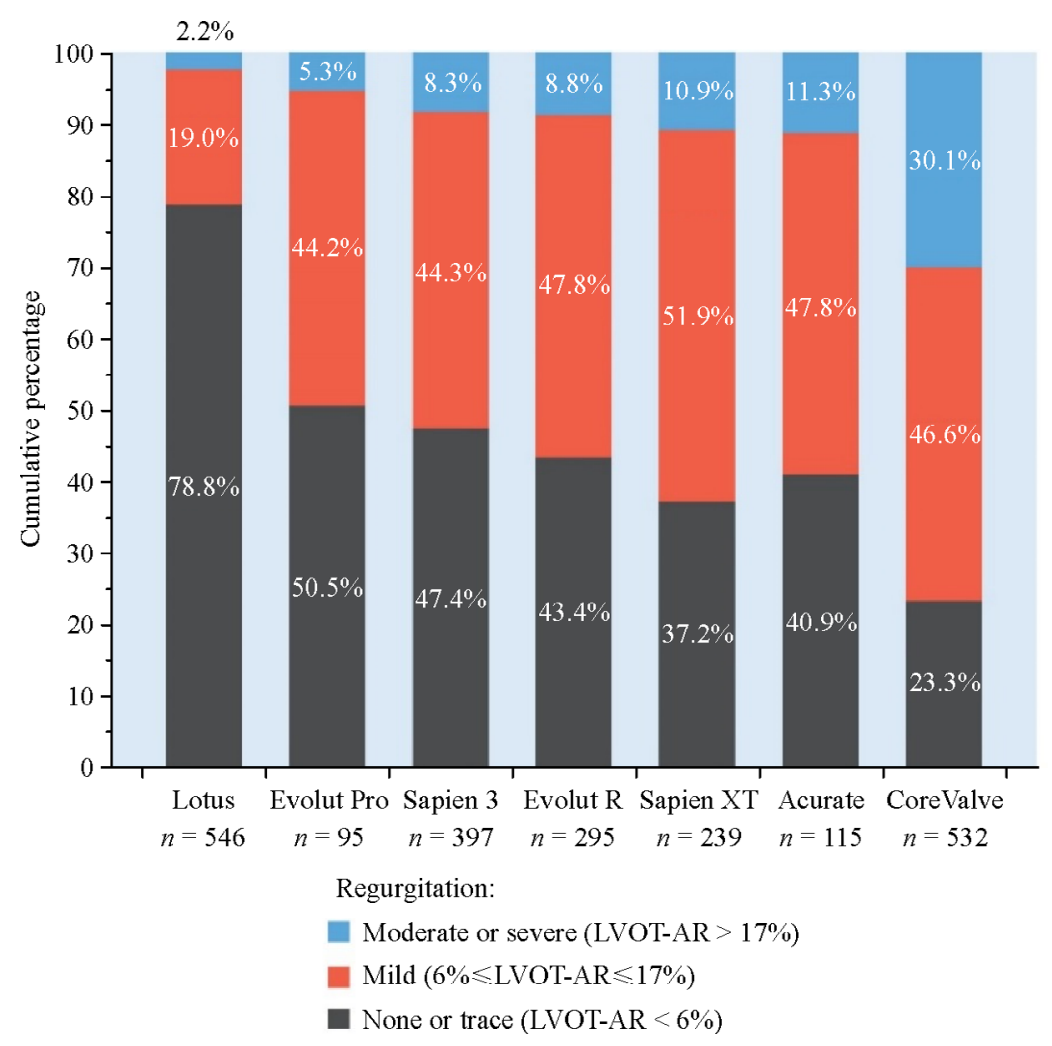

Fig. 4 Cumulative percentage of the different degree of post-TAVI aortic regurgitation assessed with quantitative aortography. The incidence of mild to moderate AR was ranged in $20 \%$ to $70 \%$ with average above $50 \%$. Second generation TAVI devices have significantly reduced the incident of moderate to severe AR but not of mild AR except for the Lotus valve. Reprinted from from Modolo et al., JACC Cardiovasc Interv, 2020; 13(11): 1303-1311.

20 years [47]. More recently, Poels et al. [48] reported 1\% PPI rate among 2279 stented AVR with mean age of 70 years. Hwang et al. [49] reported 1.5\% PPI rate following 663 stented or mechanical AVR with mean age of 67 years. Regarding the new onset LBBB after SAVR, Poels et al. reported $4.0 \%$ and $1.6 \%$ at 7 days and 3 months follow-up [48] while Hwang et al. reported $7.6 \%$ within 30 days and $4.5 \%$ after 30 days. The advantage of SAVR over TAVI in this regard was demonstrated in a randomized study. Comparing SAVR with TAVI Core valve, a significantly lower incidence of PPI, LBBB and para-valvular AR have together contributed to a more favorable LV remodelling and LV mass regression than that after TAVI [24]. During sutureless AVR (Su-AVR) the surgeon excises diseased aortic cusps and the calcification around the annulus, but as in the TAVI implantation, it also relies on prosthesis's radial force to secure its position in aortic annulus. The advantage in reducing $20 \mathrm{~min}$ of cardioplegia and cardiopulmonary time and facilitating a minimal invasive surgery or redo surgery has been offset by a significantly higher incidence of new onset LBBB (25\%-35\%) and a high degree of complete atrioventricular block that requires PPI (8\%-15\%) than those undergoing conventional SAVR [50-52]. Reports on early LVH regression and one-year survival of Su-AVR as a whole are comparable with those after conventional SAVR. Medium to long-term outcome data regarding the impact of PPI/LBBB following Su-AVR remains in paucity. Lam reported the 7-year follow-up of $58 \mathrm{Su}-\mathrm{AVR}$ cases with new onset LBBB/PPI, which had a trend of lower survival $(P=0.07)$ when compared with 807 AVR cases without LBBB/PPI [53], and the marginal statistical significance was likely due to small number of Su-VR cases thus under-powered study.

With the wider acceptance of TAVI in the elderly $(>75$ years old) population, TAVI-induced new onset LBBB (NO-LBBB) and new PPI has become the most common drawback and rendered major adverse effects on ventricular remodelling, LVH regression and the risk of sudden death in those without early PPI. Data from a variety of large TAVI trials indicates that patients with NO-LBBB did not incur significant improvement in cardiac function or LVH regression [54]. NO-LBBB results in incoordinate LV contraction and prolonged systolic tension development as is commonly caused by abnormal ventricular activation. Interestingly, an earlier study of echo strain image after TAVI suggests the NO-LBBB according to strict ECG definition showed the absence of classical mechanical desynchronise contraction pattern [55]. 
However, Calle et al. [56] reported that the septal flash is a more reliable early marker of NO-LBBB while the classical mechanical dyssynchrony in strain image may become more prevalent after cardiac contraction is significantly impaired. It is therefore a complex interaction between the afterload reduction and NO-LBBB following TAVI. Its net effects on cardiac mechanics can be variable in different patients. Nevertheless, Klaeboe et al. [57] further reported echo strain image study which showed a significant reduction in LV mechanical dispersion in TAVI patients without NO-LBBB. However, those with NOLBBB after TAVI had actually worsened mechanical dispersion and were associated with a higher risk of mortality during a 22-month follow-up (HR 1.24). The translation of incoordinate LV contraction due to LBBB/ PPI into adverse clinical outcome has been further evidenced in the latest report from Faroux et al. [58]. This is the largest meta-analysis to date and demonstrated an incidence of $23 \%$ NO-LBBB among 7792 TAVI cases and 25\% PPI in 42927 TAVI cases. At 1-year follow-up, NO-LBBB has increased the risk for all-cause mortality (HR1.32), cardiac mortality (HR 1.46), heart failure hospitalisation (HR1.35) and permanent pacemaker implantation (HR 1.89). PPI also increased risk of allcause mortality (HR 1.17) and heart failure hospitalisation (HR 1.18) but not in cardiac death. Longer term study from Jørgensen et al. [59] further showed that both NO-LBBB and PPI groups after TAVI had a worse mortality at 5-year follow-up, at $47 \%, 48 \%$ versus $33 \%$ of those without NOBBB or PPI (Fig. 5). It is also evident that the mortality curve of the PPI group was lower than NO-LBBB in the first year but it was gradually catching up with that of NOLBBB from second to third year onwards, possibly due to pacing related LV incoordinate contraction and heart failure.

Pre-existing RBBB, high degree atrioventricular block, annulus pre-dilatation, TAVI device oversizing and a lower position into LVOT during TAVI implantation are the recognized risk factors for NO-LBBB and PPI. Early PPI is indicated for high degree or complete atrioventricular (AV) block and LBBB with QRS duration over $160 \mathrm{~ms}$ with or without one-degree AV block. Currently, there is no consensus on the indication for resynchronisation therapy (CRT) or PPI for TAVI related NO-LBBB alone [60]. On the other hand, CRT with ICD for severe NO-LBBB and heart failure has been in discussion but no consensus on its indication after TAVI either. To mitigate the adverse effects of RV pacing and related LV cardiomyopathy, direct pacing of the His-Purkinje conduction system has been perused in the past 20 years. This restores an endocardial to epicardial and apex to base activation sequence. In the past 5 years, His bundle pacing and LBB based pacing have achieved early success as an alternative to right ventricular pacing for patients in bradycardia, and to bi-ventricular

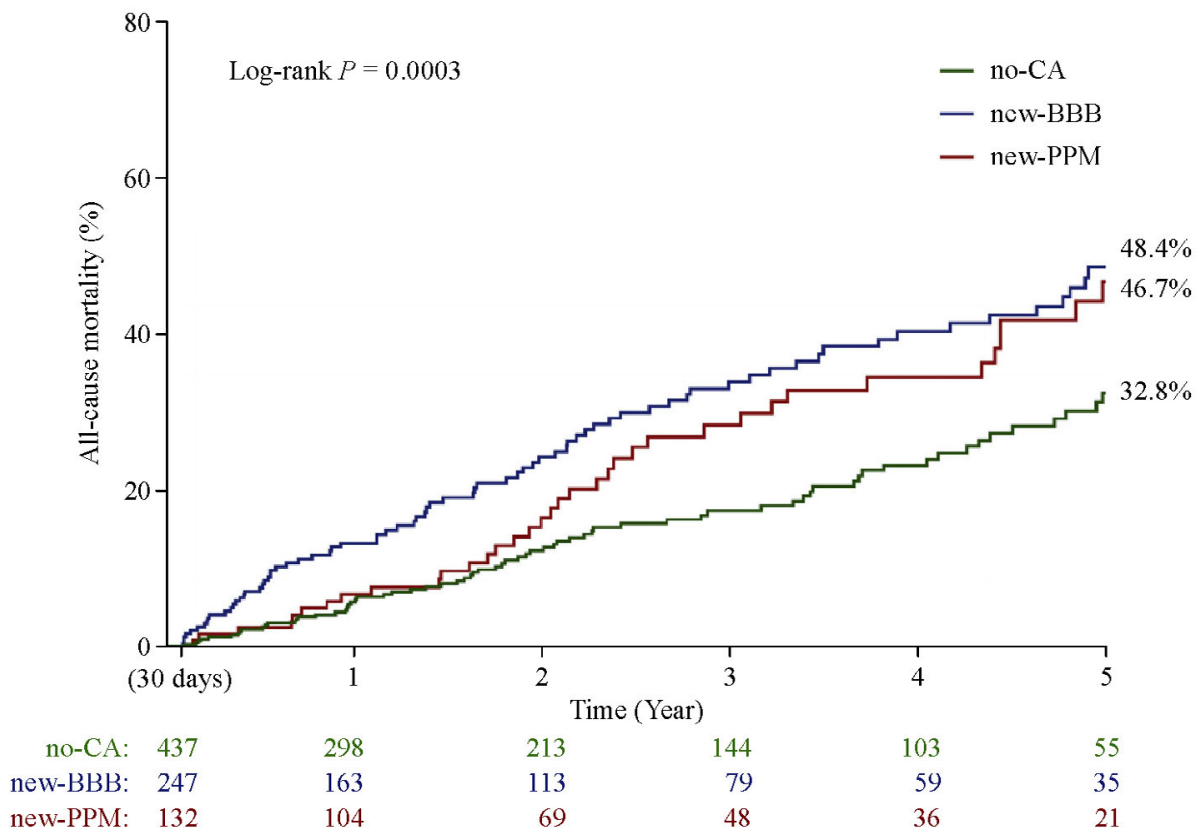

Fig. 5 Five-year absolute risk for all-cause mortality after trans-catheter aortic valve replacement (TAVA) for patients with new bundle branch block (BBB), new permanent pacemaker (PPM) or no conduction abnormalities (CA). Note that the BBB group was associated with a constant attrition rate early after TAVR while the PPM group started departure from the no-CA group from 18 months afterword and became inline with BBB group by 5 years. Modified with permission from Jørgensen et al., JACC Cardiovasc Interv, 2019 ; $12(1)$ : 52-61. 
pacing in heart failure patients undergoing CRT. Echocardiography study demonstrated improved LV contraction and reduced incoordination [61]. In patients who underwent heart valve surgery, Sharma et al. [62] used permanent His bundle pacing (HBP) in 30 patients who developed AV block post-surgery, including four TAVI cases. The success rate was $93 \%$ and the QRS duration mildly improved from $124 \pm 32$ to $118 \pm 20$ with threshold $1.45 \mathrm{~V}$ at implant. More recently De Pooter et al. [63] reported using selective or nonselective HBP in 16 patients with LBBB after TAVI. The HBP success rate was $81 \%$. Of successful ones, $69 \%$ cases had their LBBB pattern corrected on ECG and QRS duration reduced from $162 \pm 14 \mathrm{~ms}$ to $99 \pm 13 \mathrm{~ms}$, and $134 \pm 7 \mathrm{~ms}$ for selective or nonselective HBP. The threshold at 11 months followup remains stable at $1.8 \mathrm{~V}$. These are promising early experiences in TAVI cases but the HBP can be limited by the position of TAVI device in LVOT and also incurred relative high threshold voltage. More technical refinement and pacing lead renovation are ongoing. Indeed, clinical application of direct left bundle branch pacing (LBBP) and LV septal pacing (LVsP) has been successful in CRT practice, and improved LVEF in those already reduced by RV pacing or LBBB (Fig. 6) [64]. Further randomized control trials of $\mathrm{HBP} / \mathrm{LBBP} / \mathrm{LVsP}$ are warranted in TAVI with NO-LBBB along with the assessment of their clinical and physiologic benefits.

\section{Defining patients for early SAVR or TAVI by myocardial hypertrophy, fibrosis, systolic strain, and valvular-vascular coupling}

From the pathological point of view, myocardial hypertrophy is expressed as myocyte enlargement in contrast to hyperplasia, which occurs primarily in non-myocytes in the extracellular matrix (ECM) and vasculature [65]. On the other hand, Olivetti and colleagues demonstrated that the number of LV myocytes reduces significantly from age 17 to 90 years, with a loss of 38 million myocytes per year in the left ventricle, which is partially compensated by myocyte enlargement amounting to $110 \mu \mathrm{g}$ per year. The enlargement of the remaining myocytes represents a structural weakness with a reduced compensatory capacity of the aging heart [66]. This is particularly relevant for patients undergoing SAVR or TAVI, where patients are much older, and the majority have other cardiovascular comorbidities. In clinical practice, LVH is often defined by an
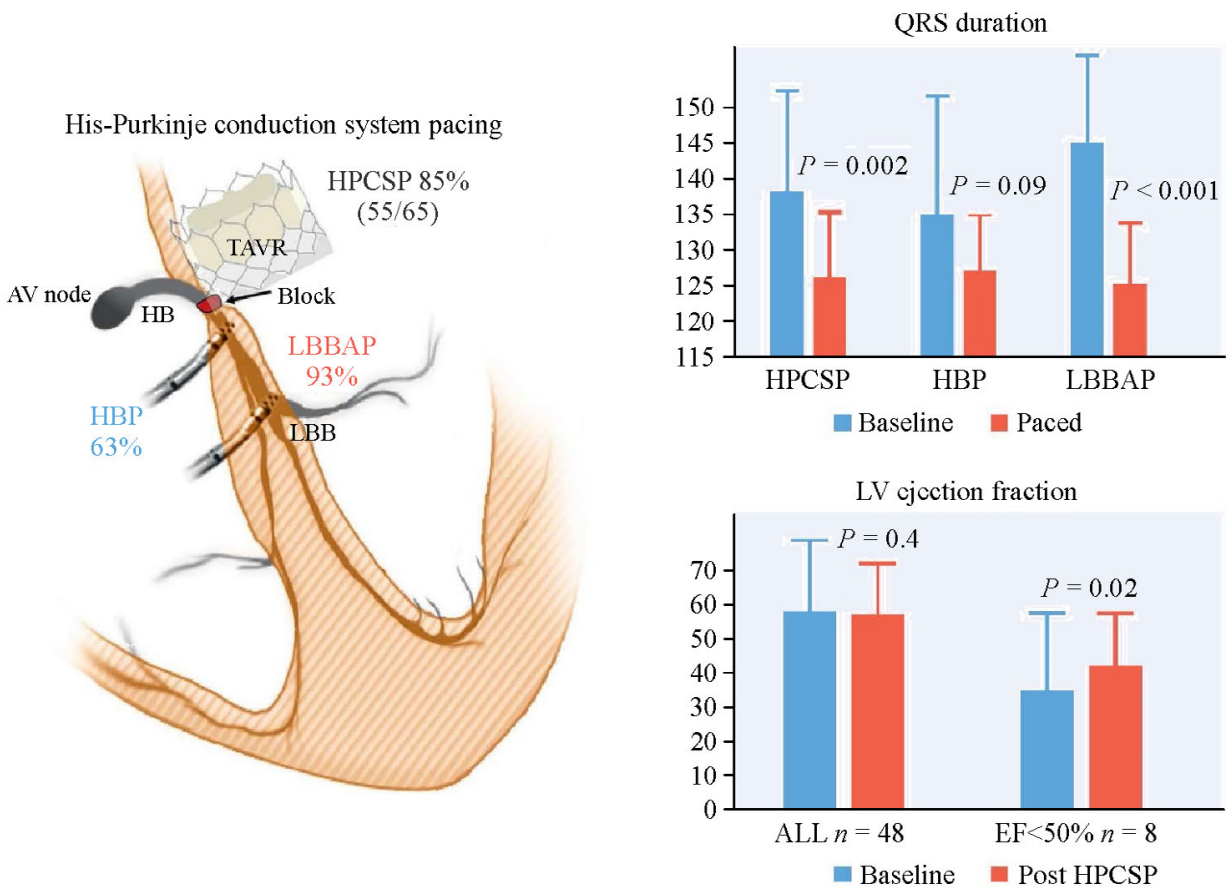

Fig. 6 Success rates, reduction in QRS duration and improvement in left ventricular ejection fraction with His-Purkinje conduction system pacing. AV, atrioventricular; EF, ejection fraction; HB, His bundle; HBP, His bundle pacing; HPCSP, His-Purkinje conduction system pacing; LBBAP, left bundle branch area pacing; LBB, left bundle branch; TAVR, transcatheter aortic valve replacement. Reprinted with permission from Vijayaraman et al., J Am Coll Cardiol EP, 2020; 6(6): 649-657. 
increase in total mass volume or ECG voltage along with strain pattern with limited recognition of two distinctive biological processes within the myocardium. Further elucidation has important clinical implications in defining patients for early SAVR or TAVI. The hallmarks of maladaptive LV remodelling are represented by increased myocardial fibrosis and stiffness. It is imperative to identify such biomarkers that are able to differentiate the transition from adaptive to maladaptive LV remodelling, hence the most appropriate time to intervene clinically. As myocyte hypertrophy represents an early and relatively reversible event in the progression of pressure overloadinduced myocardial remodelling, it seems appropriate to focus on the identification of biomarkers that are more closely associated with the myocardial ECM remodelling. Such biomarkers include transforming growth factor- $\beta 1$, cardiotrophin-1, collagen-derived peptides, the matrix metalloproteinase, and the tissue inhibitors of the matrix metallo-proteinases, and remain an area of significant scientific interest and clinical development and could in the future be combined with traditional physiological indicators to provide a more personalised approach to time the intervention.

Studies of pre-operative myocardial pathology in SAVR patients have well established that severe LVH and myocardial fibrosis predicts adverse early and late outcome. In patients who developed cardiac dysfunction the interstitial fibrosis becomes much more significant compared with those of normal function. Severe concentric LVH or septal hypertrophy proved to be associated with an increased surgical mortality or late mortality [67] in SAVR patients. Recent report from Puls et al. on TAVI patients [68] suggested that a greater burden of myocardial fibrosis was associated with 17 fold of cardiovascular mortality
(Fig. 7). The consideration for SAVR prior to the onset of adverse myocardial ECM sequelae would be valuable in patients already in severe but asymptomatic AS. With the advancement of cardiac magnetic resonance (CMR) imaging with late gadolinium enhancement (LGE) to identify those patients with significant replacement fibrosis, clinical assessment of myocardial dysfunction and fibrosis in aortic valve disease has opened up a new horizon in the past 10 years [69]. Indeed, the presence of replacement fibrosis in CMR was associated with much worse 10-year survival with HR 1.27 after SAVR [70]. On the other hand, the interstitial fibrosis measured by extracellular matrices volume expansion using CMR T1 mapping was shown to regress after AVR along with LVH regression [71]. In an effort to ensure the best possible risk/ benefit ratio, other diagnostic approaches have also been evaluated. This includes the use of the classic ECG strain pattern that commonly presents in LVH to identify those patients with significant replacement fibrosis [72]. The reduction in LV systolic global longitudinal strain (LGS) measured by echocardiography also predicts the degree of myocardial fibrosis and poorer regression of LVH after SAVR [73]. The reduction in LV basal longitudinal strain also predicts a worse MVO2 on exercise in asymptomatic moderate to severe AS patients and their cardiovascular events [74,75]. Most recently, in moderate aortic stenosis, a reduced LV global longitudinal systolic strain also predicts a higher all-cause mortality and incidence of SAVR during 6-year follow-up [76].

Aortic stenosis not only increases the afterload to ventricular ejection, it also adversely affects the fluid dynamic coupling between aortic valve and systemic circulation. Quantifying this decoupling can help clinicians better time the surgery or intervention. In the past 10 years,

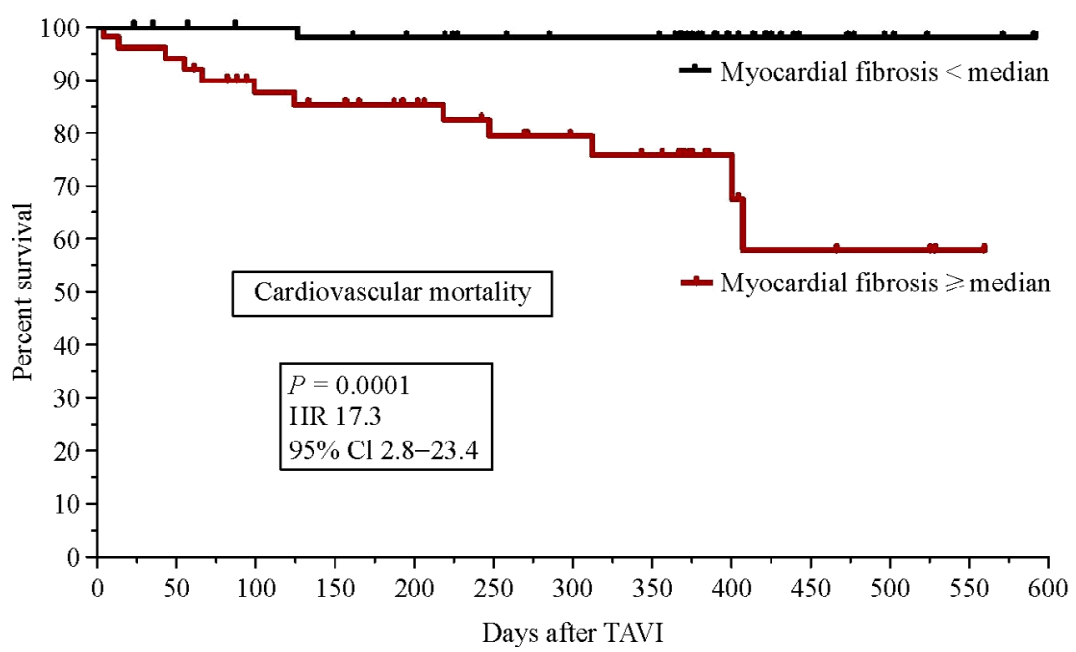

Fig. 7 Kaplan-Meier curves displaying cardiovascular mortality in patients with myocardial fibrosis below (black) and above (red) the median. Patients with significant myocardial fibrosis were associated with much worse survival after TAVI. Modified with permission from Puls et al., Eur Heart J, 2020; 41(20): 1903-1914. 
a distinctive entity of low-flow and low-gradient (LF-LG) symptomatic AS with normal LVEF has been well recognized in patients who have a small LV stroke volume index (LV SVI) $<35 \mathrm{~mL} / \mathrm{m}^{2}$ and mean gradient $<40$ mmHg. Eleid et al. [77] reported the 2-year survival of 1704 AS patients with preserved LVEF regarding their flow-gradient status. The LF-LG aortic stenosis patients revealed the highest early mortality risk with HR 3.26. But those undergoing SAVR enjoyed a reduction in mortality of $69 \%$, very similar to those patients with normal flow-high gradient (NF-HG). However, in a larger data set from a network meta-analysis of 9737 SAVR patients, Zheng et al. [78] reported that early mortality reduction was greatest in NF-HG by AVR with HR 0.34 but least in LF-LG, HR 1.19. This apparent discrepancy requires further physiologic and fluid dynamic consideration. Firstly, by calculating the energy loss index of these severe AS patients with normal LVEF based on routine echo assessment, Altes et al. [79] reported that up to $40 \%$ of cases could be reclassified from severe into moderate AS, thus no longer requiring immediate surgical intervention. Secondarily, the LF-LG AS is frequently associated with systemic hypertension, which is known to have a major impact on the hemodynamic performance of the stenotic aortic valve and left ventricle. By incorporating the energy loss concept further with the aortic vascular impedance theory, the valvular-vascular impedance (Z-va) can be calculated $(\mathrm{Z}-\mathrm{va}=($ mean $\mathrm{AV}$ PG $+\mathrm{BPs}) / \mathrm{LV} \mathrm{SVI})$, which has been validated for reflecting the actual total afterload to LV contraction. Hachicha et al. [80] have shown that Z-va predicts those with poor outcome in 544 asymptomatic AS patients using a cut-off at $3.5 \mathrm{mmHg} / \mathrm{mL} / \mathrm{m}^{2}$. The same investigators had further reported that in 512 asymptomatic severe AS patients, the group of LF-LG AS had a higher Zva and worse outcome due to being in a more advanced stage of disease [81]. Cramariuc et al. studied LV function of 1591 cases with asymptomatic low flow AS using midwall shortening wall stress relationship stratified by Z-va tertile. It was demonstrated that the LV global afterload (Zva) was a main predictor of lower stress-corrected mid wall shortening, independent from LV geometry, hypertrophy, and hypertension, despite of mean LVEF all at 60\% [82]. In TAVI patients, Nuis et al. [83] reported an elevated Z-va occurred in half of the patients at base line and reduced to $21 \%$ at 1 year after TAVI, but the patients who had remained to have elevated Z-va were associated with poor quality of life and exercise performance.

The above pathological and physiologic based approaches have offered a range of diagnostic capability for better defining the risk-benefit ratio in early SAVR or TAVI. Recent cohort studies demonstrated an improved outcome if SAVR were undertaken early following the diagnosis. This notion has been supported by a randomized trial of 145 AS cases reported by Kang et al. [84]. The early AVR versus medical management had a major reduction of primary endpoint (event of death) by HR 0.09 . Currently there are several ongoing randomized trials, EVOLVED, AVATAR, and others, which are expected to provide more robust data and the criteria for early valve intervention in the near future [85].

\section{Renin-angiotensin system inhibitors and improvement in LV remodelling and clinical prognosis in SAVR and TAVI}

Despite the promising better outcome through early SAVR or TAVI, in current clinical practice, many AS or AR patients present first time with an already advanced disease stage and heart failure. In addition, the co-morbidity and valve procedure related complications also require ongoing medical therapy after the surgery. Furthermore, the AS or $\mathrm{AR}$ in aging patients is often part of a systemic biological disease, therefore their treatment by renin-angiotensin system inhibitors (RASI) would be a logical consideration before and/or after the surgery. There were however many sceptics two decades ago due to the safety concerns of RASI in AS patient. The turning point came after the report of a large clinical cohort study. Nadir et al. [86] reported a retrospective study of 2117 AS patients with a mean follow-up of 4.2 years. Of 699 cases on ACEI or ARBII, they were associated with a significantly lower all-cause mortality and CV event, HR $0.76,0.77$, respectively. The effects of ACEI on LV mass in asymptomatic AS were studied by Bull et al. [87] in a randomized clinical trial of 100 moderate to severe AS patients using CMR image, and demonstrated a modest reduction of LV mass in 12 months follow-up.

In cardiac surgery, peri-operative use of RASI was conducted in a multicenter cohort study of over 8500 cases. Ding et al. [88] reported those who received the RASI treatment before surgery had a lower 30-day mortality, $3.4 \%$ versus $5.0 \%$ than those who did not; and those received the RASI after the surgery also benefited to 2-year and 6-year mortality. Prospective randomized investigation of 114 patients demonstrated that candesartan achieved greater LV mass regression, 30 verses $12 \mathrm{~g} / \mathrm{m}^{2}$, at 12 months [89]. Combining ACE-i and ARB II blockade enhanced the LVH regression after SAVR in the presence of PPM [90]. Geol et al. [91] reported a large cohort study of 1752 SAVR cases for AS together with propensity matched analysis of 594 pairs, showing the beneficial effects of RASI in up to 10-year survival (Fig. 8). This was however not associated with a greater LVEF or LV mass regression, implying the underlying mechanism of RASI is likely beyond the ventricular remodelling. Magne et al. [92] reported a consecutive 508 SAVR cases for AS, and demonstrated a better 8 years survival ( $82 \%$ versus $53 \%$ ) for those on RASI treatment. In addition, ARB II was associated with a lower 30 -day mortality $(0.7 \%$ vs. $5.6 \%)$ 


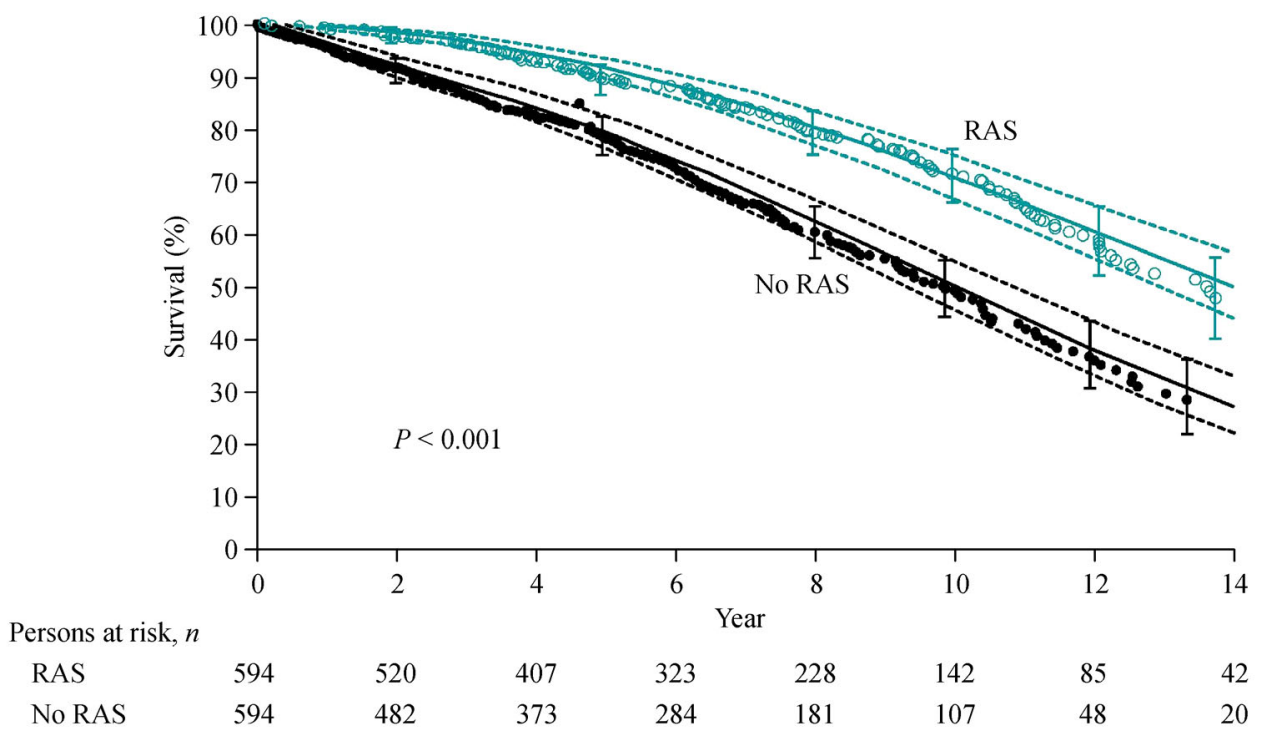

Fig. 8 Long-term survival curves after SAVR in propensity matched groups that were stratified by RAS blockade therapy. Patients on the therapy were associated with a better long-term survival. Each symbol represents a death, and vertical bars represent $95 \%$ CIs estimated by Kaplan-Meier method. Solid lines are parametric estimates enclosed within a 95\% confidence band. RAS, renin-angiotensin system; SAVR, surgical aortic valve replacement. Modified with permission from Goel et al., Ann Intern Med, 2014; 161(10): 699-710.

than those on ACEI. In TAVI patients, the benefits of RASI were first reported by Ochiai et al. [93] as a retrospective cohort study from the OCEAN-TAVI registry. The study compared 189 cases with RASI versus 371 cases without, and demonstrated a greater LV mass regression at 6 months, a lower 2-year all-cause mortality with HR 0.45 . RASI was also protective of the patients with significant para-valvular AR. Data from STS/ACC TAVI register of 21312 cases was reported by Inohara et al. [94], which showed that among 8469 cases with the treatment of RASI after the TAVI procedure there were benefits to survival and hospital readmission at 1 year. A report from the RASTAVI cohort study with 2785 cases and 10-year follow-up [95] demonstrated that ACE-i benefited to LV remodelling in terms of LV volume, mass regression and 3year cardiac mortality ( $3.5 \%$ vs. $5.8 \%$ ), along with a lower incidence in new AF, cerebrovascular events. It thus provided global protection to the cardiovascular system. The observed benefits of ACEI are very encouraging but cannot be determined as a causal relationship to the RASI, as the patients' treatment was not randomly assigned. Large scale RCT in SAVR or TAVI is warranted.

\section{Age specific control of hypertension and $A F$ after SAVR and TAVI}

Atrial fibrillation has major deleterious effects on left ventricular remodelling and long-term outcome after
SAVR and TAVI. It results in the loss of atrial contraction thus reducing LV longitudinal functional recovery after SAVR. The underlying mechanism is more complex than a simple shift of the LV operating position on the Starling curve, due to the changes in LV geometry becoming more spherical and regional contraction profiles becoming more dependent on circumferential direction. These physiologic mechanisms underlie long established clinical findings that $\mathrm{AF}$ is an independent risk factor for long-term survival after SAVR. AF ablation during SAVR has been performed and has significantly improved the rate of sinus rhythm and reduced the incidence of thromboembolic events in cohort studies. The data on survival benefit remains inconclusive, in part, $\mathrm{AF}$ is often considered as a marker of advanced disease stage in SAVR patients. Similar findings were confirmed by subsequent RCTs in SAVR patients and their meta-analysis. Following TAVI, the incidence of new onset $\mathrm{AF}$ is half of that after SAVR. However, both pre-existing and new onset of $\mathrm{AF}$ remain to be associated with a significantly worse outcome $[96,97]$. In particular, AF patients with a response rate above $90 \mathrm{bpm}$ have an even worse 1-year mortality after TAVI $(40 \%$ vs. $26 \%$, $P<0.005$ ), and thus require effective rate control by medications.

Hypertension is present in $60 \%-80 \%$ of elderly aortic stenosis patients and plays a highly important role in the development and regression of LVH in patients with aortic valve disease and surgery. It causes the baseline LVH to be much greater at a given degree of aortic valve disease, with 
a more severe concentrical LV geometry and a lower LV stroke volume, thus complicating the assessment of the degree of aortic stenosis as has been discussed earlier. Its presence also continuously diminishes the long-term LVH regression after surgery. An early report [98] elegantly demonstrated two different patterns of LVH regression after SAVR, the significant and sustained LVH regression in those without hypertension versus a slow and insignificant regression in those with ongoing hypertension. This pattern was also demonstrated in patients undergoing stentless AVR in that the hypertension was a major factor causing residual hypertrophy with late upswings at medium term $[28,99]$. These findings have supported a more robust and prospective control of hypertension after SAVR, and were demonstrated to be beneficial to postoperative LVH regression [100]. However, these clinical experiences were derived from studies in SAVR patients with mean age of 60-70 years. In TAVI and more elderly SAVR patients with a mean age of 80 years or above, their optimal blood pressure (BP) control after surgery can be complex and differ from conventional hypertension management. Lindman et al. [101] recently studied 1794 TAVI cases and 1103 SAVR cases, and demonstrated that patients with a diastolic blood pressure (BPd) below 60 $\mathrm{mmHg}$ and systolic blood pressures (BPs) below 120 $\mathrm{mmHg}$ had a $60 \%$ relative increase in first year mortality compared with those with BPd $60-80 \mathrm{mmHg}$ and BPs 120-150 mmHg (Fig. 9A and 9B). In contrast, these patients with BPd $>80 \mathrm{mmHg}$ and BPs $>150 \mathrm{mmHg}$ did not have an increased first year mortality. These findings imply that elderly patients with $\mathrm{LVH}$ and/or CAD require a much higher coronary perfusion pressure after SAVR or TAVI, particularly when there is an ongoing fast AF, LBBB, PPI, and residual AR. These findings suggest that we need more specific guidelines on blood pressure management in elderly TAVI and SAVR patients.

\section{Is TAVI ready for the prime time in low risk and younger AS patients?}

Recently TAVI has been advocated as a superior or noninferior alternative to conventional SAVR in low-risk AS patients, based on 1-year composite endpoints of death, stroke, and rehospitalisation [102,103]. The enthusiasm of expanding TAVI into low-risk elderly patients is probably reasonable but to march TAVI into younger patients (age below 70-75 years) with low surgical risk remains in question, especially many of more prevalent risks were not addressed in these trials.

Firstly, there is very limited medium to long-term data regarding the durability of TAVI devices. The longestablished consensus from SAVR requires a proven durability of $12-15$ years for a new bioprostheses to be widely implanted in the age group of 60-70 years.
Although UK TAVI register reported $85 \%$ of freedom from structural valve deterioration (SVD) at 5-year followup in patient aged 81 years [104], this is insufficient to be extrapolated into a younger age group, not least the findings were based on the early generation of TAVI devices with less than $30 \%$ of patients survived to five years. Others have used valve prosthesis pressure gradient or its changes over time as the criteria of SVD and claimed a lower SVD rate of TAVI than SAVR in 6-year follow-up but unable to show any significant difference in clinical outcome or reoperation [105].

Secondly, the TAVI device's risk of obstructing coronary ostia is increasingly recognized. Ochiai et al. reported the incidence of unfavorable coronary access identified by CT as being $16 \%$ and $35 \%$ to left coronary and $8 \%, 26 \%$ to right coronary following SAPIEN 3 or Evolute R/PRO respectively [106]. The successful rate of actual coronary catheterization was as low as $33 \%$ and $0 \%$ compared with $91 \%$ and $78 \%$ of those without CT evidence of unfavorable access. The self-expansion TAVI has a higher skirt and smaller open cell size than the balloon expansion TAVI thus producing a greater risk of restricting the access to coronary ostia (Fig. 10) [107]. In the case of TAVI valvein-valve for those who had first time TAVI implant, unfeasible coronary access occurs in over $30 \%$ of patients [108]. This has raised significant concerns for TAVI in AS patients at low risk and of a younger age who are more likely than older higher risk patients to require coronary angiography and intervention, as well as further valve intervention. TAVI valve-in-SAVR appears to be a feasible and safe alternative to redo SAVR for degenerative bioprostheses. Recently the meta-analysis of 594 patients reported by Nalluri et al. demonstrated that TAVI valve- inSAVR provided a comparable 30 -day mortality ( $4.5 \%$ vs. $4.8 \%$ ) with that of redo SAVR [109]. However, the surgical explantation of TAVI device can be a much more morbid procedure with technical challenges both in removing the TAVI device and replacing it with SAVR. Fukuhara et al. reported 782 cases of surgical replacement of TAVI device from US Society of Thoracic Surgeon database. The 30day mortality was $19.4 \%$ which was $54 \%$ higher than expected risk by STS score. In addition, $56 \%$ of cases required concomitant procedures including coronary bypass graft, aortic root and ascending aorta replacement and/or mitral valve surgeries [110].

Thirdly, the incidence of clinical leaflet thrombus in TAVI is at $4.5 \%$ per year while that of subclinical leaflet thickening is $15 \%$ per year. The stroke rate and TIA rate was 7-fold and 5-fold compared to those without leaflet thrombosis [111,112]. Of note, the balloon expansion TAVI device has a greater risk for leaflet thrombosis than the self-expansion TAVI, due to a smaller space in the neosinuses thus a weaker washing flow [113]. Oral anticoagulation is more effective than dual-antiplatelet agent in resolving the leaflet thrombosis and reducing the raised 

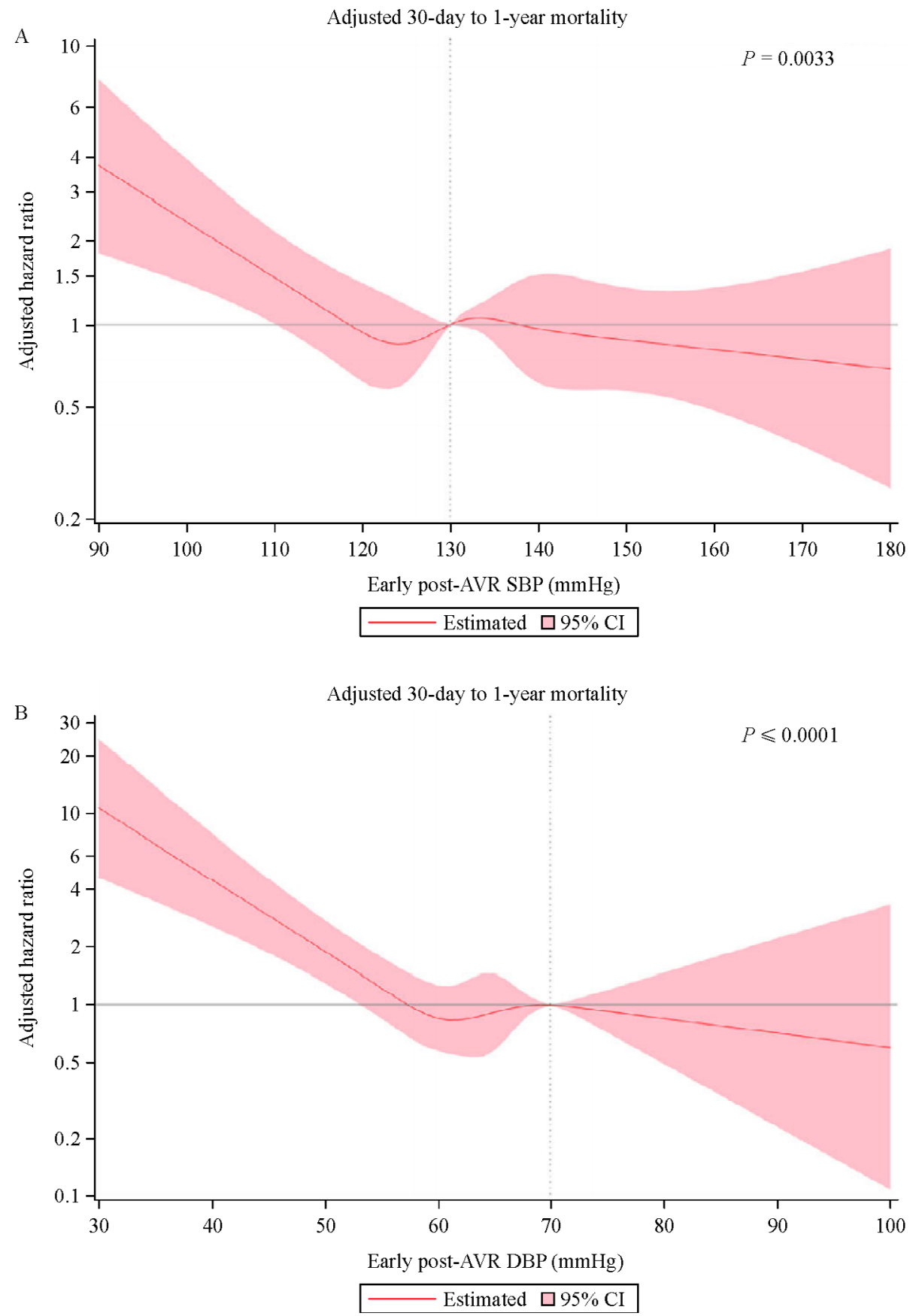

Fig. 9 (A) All-cause 30-day to 1-year mortality after aortic valve replacement as a function of systolic blood pressure is analyzed in Cox proportional hazard models using restricted cubic splines technique. This identified worsening outcome for those with systolic blood pressure below 115-120 mmHg. (B) All-cause 30-day to 1-year mortality after aortic valve replacement as a function of diastolic blood pressure is analyzed in Cox proportional hazard models using restricted cubic splines technique. This identified worsening outcome for those with diastolic blood pressure below 55-60 mmHg. Modified with permission from Lindman et al., J Am Heart Assoc, 2019; 8(21): $100-129$.

TAVI pressure gradient.

Clearly, to consider TAVI for low-risk patients at a younger age (below 70-75 years), the clinician lacks comprehensive data to quantify all the risks for a given patient that have been discussed above. In contrast, if these low-risk patients undergo a conventional SAVR, they would not encounter many of the above TAVI related risks, and will have a more predictable long-term durability and simpler management. Arguably, the SAVR should remain as the first line choice for the index surgery, and TAVI 

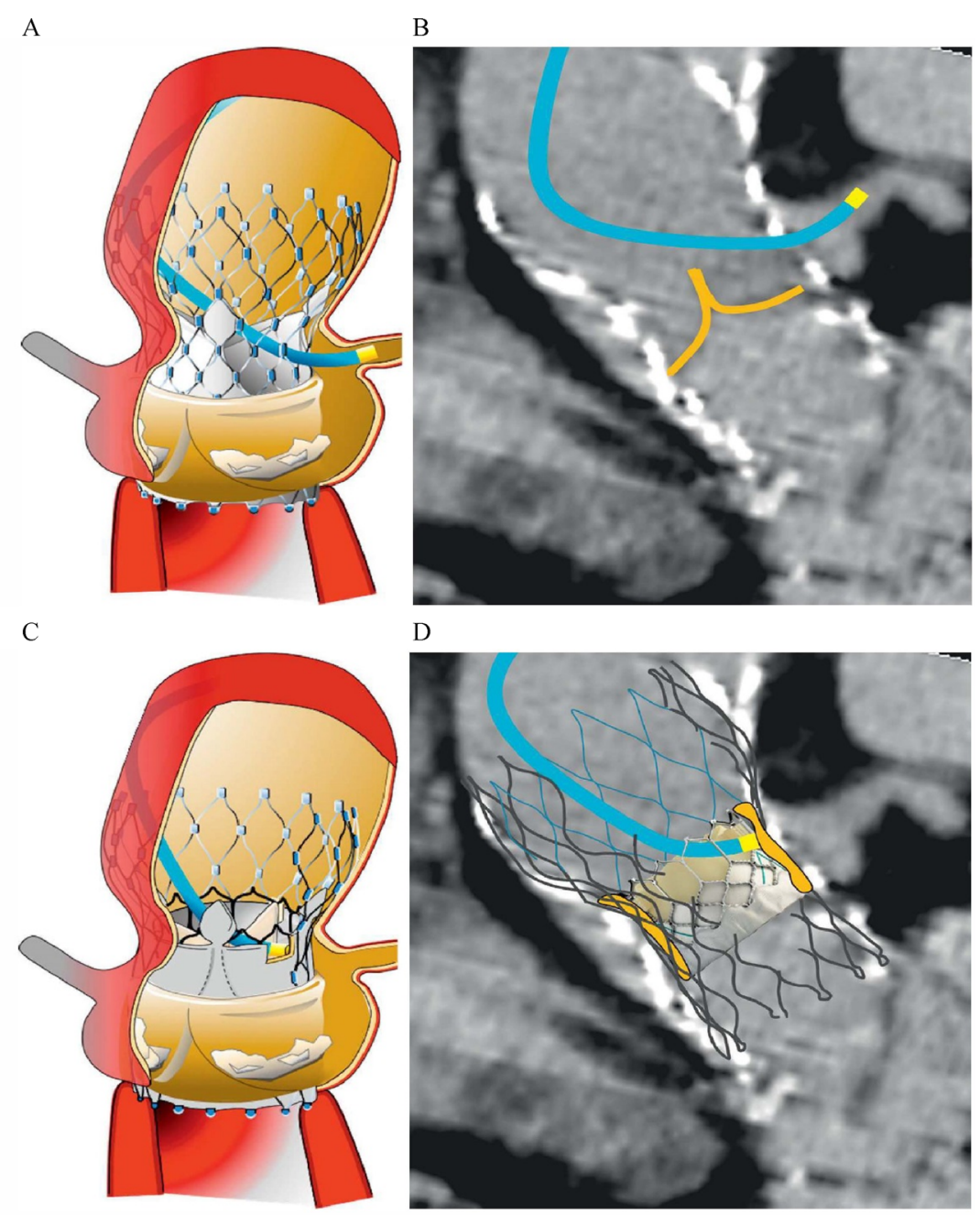

Fig. 10 Concept of impaired coronary access after TAVI-in-TAVI. After the implantation of a single TAVI prosthesis, catheters can reach the coronary ostium through its open-cell stent frame (A and B). The implantation of a second device inside the previous pushes and spreads out the old leaflets along the stent, making it "covered" and not crossable anymore (C and D). The loss of stent free-flow together with the overlap of the 2 metallic stent frames even above the leaflet level will impair catheter navigation inside the aortic root and coronary cannulation. Modified with permission from Buzzatti et al., JACC Cardiovasc Imaging, 2020; 13(2 Pt 1): 508-515.

could be reserved for when the redo surgery for SAVR becomes indicated some 12-15 years later. By then these patients will be older and have a risk profile more justifying a TAVI-in-SAVR solution.

\section{Summary}

Over the last half century, surgical aortic valve replacement has evolved to offer a durable and efficient valve hemodynamic performance with a lower procedural complication. This allows favorable remodelling of left ventricular structure and function. The latter has become more challenging among the elderly population following trans-catheter aortic valve replacement. Precise understanding of myocardial adaptation to pressure and volume overload and its responses to valve surgery requires comprehensive physiologic assessments from aortic valve energy loss and valvular-vascular impedance to myocardial activation, force-velocity relationship and myocardial strain. Left ventricular hypertrophy and myocardial fibrosis remains the structural and morphological focus in this endeavor. Early intervention in asymptomatic aortic stenosis or regurgitation along with individualised management of hypertension and atrial fibrillation is likely to improve patient outcome. Physiologic pacing via the His-Purkinje system for conduction abnormalities, further reduction in para-valvular aortic regurgitation and systematic treatment with angiotensin receptor blockade will improve patient outcome by facilitating hypertrophy regression, LV coordinate contraction and global vascular function. Obstruction by the 
TAVI device of the coronary ostia imposes a significant access risk to TAVI-in-TAVI and future coronary interventions. Until comparable long-term durability and effective mitigation of TAVI related complications, surgical AVR remains the first choice for lower risk younger AS patients.

\section{Acknowledgements}

The authors received financial support for the research work in cardiac physiology and aortic valve surgery by research grant from Garfield Weston Trust, London (to Xu Yu Jin and John R Pepper) and from Oxford Hospital Charity, Oxford (to Xu Yu Jin).

\section{Compliance with ethics guideline}

Xu Yu Jin, Mario Petrou, Jiang Ting Hu, Ed D Nicol, and John R Pepper declared no potential conflict of interests with respect to the research, authorship and/or publication of this article. This manuscript is a review article and does not involve a research protocols requiring approval by the relevant institutional review board of ethics committee.

Open Access This article is licensed under a Creative Commons Attribution 4.0 International License, which permits use, sharing, adaptation, distribution and reproduction in any medium or format, as long as you give appropriate credit to the original author(s) and the source, provide a link to the Creative Commons licence, and indicate if changes were made.

The images or other third party material in this article are included in the article's Creative Commons licence, unless indicated otherwise in a credit line to the material. If material is not included in the article's Creative Commons licence and your intended use is not permitted by statutory regulation or exceeds the permitted use, you will need to obtain permission directly from the copyright holder.

To view a copy of this licence, visit http://creativecommons.org/ licenses/by/4.0/.

\section{References}

1. Glaser N, Persson M, Jackson V, Holzmann MJ, Franco-Cereceda A, Sartipy U. Loss in life expectancy after surgical aortic valve replacement: SWEDEHEART Study. J Am Coll Cardiol 2019; 74 (1): 26-33

2. Parikh R, Goodman AL, Barr T, Sabik JF, Svensson LG, Rodriguez LL, Lytle BW, Grimm RA, Griffin BP, Desai MY. Outcomes of surgical aortic valve replacement for severe aortic stenosis: Incorporation of left ventricular systolic function and stroke volume index. J Thorac Cardiovasc Surg 2015; 149(6): 1558-66.e1

3. Jin XY, Pepper JR, Brecker SJ, Carey JA, Gibson DG. Early changes in left ventricular function after aortic valve replacement for isolated aortic stenosis. Am J Cardiol 1994; 74(11): 1142-1146
4. Jin XY, Pepper JR, Gibson DG, Yacoub MH. Early changes in the time course of myocardial contraction after correcting aortic regurgitation. Ann Thorac Surg 1999; 67(1): 139-145

5. Jin XY, Pepper JR, Gibson DG. Effects of incoordination on left ventricular force-velocity relation in aortic stenosis. Heart 1996; 76 (6): 495-501

6. Ito S, Pislaru C, Miranda WR, Nkomo VT, Connolly HM, Pislaru SV, Pellikka PA, Lewis BR, Carabello BA, Oh JK. Left ventricular contractility and wall stress in patients with aortic stenosis with preserved or reduced ejection fraction. JACC Cardiovasc Imaging 2020; 13(2 Pt 1): 357-369

7. Prihadi EA, Vollema EM, Ng ACT, Ajmone Marsan N, Bax JJ, Delgado V. Determinants and prognostic implications of left ventricular mechanical dispersion in aortic stenosis. Eur Heart $\mathrm{J}$ Cardiovasc Imaging 2019; 20(7): 740-748

8. Slimani A, Melchior J, de Meester C, Pierard S, Roy C, Amzulescu M, Bouzin C, Maes F, Pasquet A, Pouleur AC, Vancraeynest D, Gerber B, El Khoury G, Vanoverschelde JL. Relative contribution of afterload and interstitial fibrosis to myocardial function in severe aortic stenosis. JACC Cardiovasc Imaging 2020; 13 (2 Pt 2): 589600

9. Reichek N. Afterload and fibrosis: aortic stenosis co-conspirators. JACC Cardiovasc Imaging 2020; 13(2 Pt 2): 601-603

10. Hess OM, Villari B, Krayenbuehl HP. Diastolic dysfunction in aortic stenosis. Circulation 1993; 87(5 Suppl): IV73-IV76

11. Thaden JJ, Balakrishnan M, Sanchez J, Adigun R, Nkomo VT, Eleid M, Dahl J, Scott C, Pislaru S, Oh JK, Schaff H, Pellikka PA. Left ventricular filling pressure and survival following aortic valve replacement for severe aortic stenosis. Heart 2020; 106(11): 830837

12. Ong G, Pibarot P, Redfors B, Weissman NJ, Jaber WA, Makkar RR, Lerakis S, Gopal D, Khalique O, Kodali SK, Thourani VH, Anwaruddin S, McAndrew T, Zhang Y, Alu MC, Douglas PS, Hahn RT. Diastolic function and clinical outcomes after transcatheter aortic valve replacement: PARTNER 2 SAPIEN 3 Registry. J Am Coll Cardiol 2020; 76(25): 2940-2951

13. Villari B, Sossalla S, Ciampi Q, Petruzziello B, Turina J, Schneider J, Turina M, Hess OM. Persistent diastolic dysfunction late after valve replacement in severe aortic regurgitation. Circulation 2009; 120(23): 2386-2392

14. Gjertsson P, Caidahl K, Farasati M, Odén A, Bech-Hanssen O. Preoperative moderate to severe diastolic dysfunction: a novel Doppler echocardiographic long-term prognostic factor in patients with severe aortic stenosis. J Thorac Cardiovasc Surg 2005; 129 (4): 890-896

15. Lund O, Emmertsen K, Dørup I, Jensen FT, Flø C. Regression of left ventricular hypertrophy during 10 years after valve replacement for aortic stenosis is related to the preoperative risk profile. Eur Heart J 2003; 24(15): 1437-1446

16. Head SJ, Mokhles MM, Osnabrugge RL, Pibarot P, Mack MJ, Takkenberg JJ, Bogers AJ, Kappetein AP. The impact of prosthesis-patient mismatch on long-term survival after aortic valve replacement: a systematic review and meta-analysis of 34 observational studies comprising 27186 patients with 133141 patient-years. Eur Heart J 2012; 33(12): 1518-1529

17. Mohty D, Dumesnil JG, Echahidi N, Mathieu P, Dagenais F, Voisine P, Pibarot P. Impact of prosthesis-patient mismatch on 
long-term survival after aortic valve replacement: influence of age, obesity, and left ventricular dysfunction. J Am Coll Cardiol 2009; 53(1): 39-47

18. Jin XY, Westaby S. In vivo hemodynamic characteristics of porcine stentless aortic valves. Semin Thorac Cardiovasc Surg 2001; $13(4$ Suppl 1): 67-74

19. Pillai R, Ratnatunga C, Soon JL, Kattach H, Khalil A, Jin XY. $3 f$ prosthesis aortic cusp replacement: implantation technique and early results. Asian Cardiovasc Thorac Ann 2010; 18(1): 13-16

20. Jin XY, Westaby S. Aortic root geometry and stentless porcine valve competence. Semin Thorac Cardiovasc Surg 1999; 11(4 Suppl 1): 145-150

21. Liao YB, Li YJ, Jun-Li L, Zhao ZG, Wei X, Tsauo JY, Xiong TY, $\mathrm{Xu}$ YN, Feng Y, Chen M. Incidence, predictors and outcome of prosthesis-patient mismatch after transcatheter aortic valve replacement: a systematic review and meta-analysis. Sci Rep 2017; 7 (1): 15014

22. Pibarot P, Weissman NJ, Stewart WJ, Hahn RT, Lindman BR, McAndrew T, Kodali SK, Mack MJ, Thourani VH, Miller DC, Svensson LG, Herrmann HC, Smith CR, Rodés-Cabau J, Webb J, Lim S, Xu K, Hueter I, Douglas PS, Leon MB. Incidence and sequelae of prosthesis-patient mismatch in transcatheter versus surgical valve replacement in high-risk patients with severe aortic stenosis: a PARTNER trial cohort - a analysis. J Am Coll Cardiol 2014; 64(13): 1323-1334

23. Poulin F, Yingchoncharoen T, Wilson WM, Horlick EM, Généreux P, Tuzcu EM, Stewart W, Osten MD, Woo A, Thavendiranathan P. Impact of prosthesis-patient mismatch on left ventricular myocardial mechanics after transcatheter aortic valve replacement. J Am Heart Assoc 2016; 5(2): e002866

24. Ngo A, Hassager C, Thyregod HGH, Søndergaard L, Olsen PS, Steinbrüchel D, Hansen PB, Kjærgaard J, Winther-Jensen M, Ihlemann N. Differences in left ventricular remodelling in patients with aortic stenosis treated with transcatheter aortic valve replacement with corevalve prostheses compared to surgery with porcine or bovine biological prostheses. Eur Heart J Cardiovasc Imaging 2018; 19(1): 39-46

25. Jin XY, Zhang ZM, Gibson DG, Yacoub MH, Pepper JR. Effects of valve substitute on changes in left ventricular function and hypertrophy after aortic valve replacement. Ann Thorac Surg 1996; 62(3): 683-690

26. Kunadian B, Vijayalakshmi K, Thornley AR, de Belder MA, Hunter S, Kendall S, Graham R, Stewart M, Thambyrajah J, Dunning J. Meta-analysis of valve hemodynamics and left ventricular mass regression for stentless versus stented aortic valves. Ann Thorac Surg 2007; 84(1): 73-78

27. Jin XY, Ratnatunga C. Invited commentary. Ann Thorac Surg 2007; 84(1): 78-79

28. Jin $X Y$. Elucidation of cardiac physiology in aortic valve replacement: what should we know? J Heart Valve Dis 2004; 13 (Suppl 1): S70-S75

29. Beach JM, Mihaljevic T, Rajeswaran J, Marwick T, Edwards ST, Nowicki ER, Thomas J, Svensson LG, Griffin B, Gillinov AM, Blackstone EH. Ventricular hypertrophy and left atrial dilatation persist and are associated with reduced survival after valve replacement for aortic stenosis. J Thorac Cardiovasc Surg 2014; 147(1): 362-369.e8
30. Gonzales H, Douglas PS, Pibarot P, Hahn RT, Khalique OK, Jaber WA, Cremer P, Weissman NJ, Asch FM, Zhang Y, Gertz ZM, Elmariah S, Clavel MA, Thourani VH, Daubert M, Alu MC, Leon MB, Lindman BR. Left ventricular hypertrophy and clinical outcomes over 5 years after TAVR: an analysis of the PARTNER trials and registries. JACC Cardiovasc Interv 2020; 13(11): 13291339

31. Chau KH, Douglas PS, Pibarot P, Hahn RT, Khalique OK, Jaber WA, Cremer P, Weissman NJ, Asch FM, Zhang Y, Gertz ZM, Elmariah S, Clavel MA, Thourani VH, Daubert M, Alu MC, Leon MB, Lindman BR. Regression of left ventricular mass after transcatheter aortic valve replacement: the PARTNER trials and registries. J Am Coll Cardiol 2020; 75(19): 2446-2458

32. Jin XY, Pillai R, Westaby S. Medium-term determinants of left ventricular mass index after stentless aortic valve replacement. Ann Thorac Surg 1999; 67(2): 411-416

33. van Dalen BM, Tzikas A, Soliman OI, Kauer F, Heuvelman HJ, Vletter WB, ten Cate FJ, Geleijnse ML. Left ventricular twist and untwist in aortic stenosis. Int J Cardiol 2011; 148(3): 319-324

34. Carasso S, Cohen O, Mutlak D, Adler Z, Lessick J, Aronson D, Reisner SA, Rakowski H, Bolotin G, Agmon Y. Relation of myocardial mechanics in severe aortic stenosis to left ventricular ejection fraction and response to aortic valve replacement. Am J Cardiol 2011; 107(7): 1052-1057

35. Meyer CG, Frick M, Lotfi S, Altiok E, Koos R, Kirschfink A, Lehrke M, Autschbach R, Hoffmann R. Regional left ventricular function after transapical vs. transfemoral transcatheter aortic valve implantation analysed by cardiac magnetic resonance feature tracking. Eur Heart J Cardiovasc Imaging 2014; 15(10): 11681176

36. Deng MD, Wei X, Zhang XL, Li XD, Liu GY, Zhu D, Guo YQ, Tang H. Changes in left ventricular function in patients with aortic regurgitation 12 months after transapical transcatheter aortic valve implantation. Int J Cardiovasc Imaging 2019; 35(1): 99-105

37. Ribeiro HB, Dahou A, Urena M, Carrasco JL, Mohammadi S, Doyle D, Le Ven F, Allende R, Amat-Santos I, Paradis JM, DeLarochellière R, Puri R, Abdul-Jawad Altisent O, del Trigo M, Campelo-Parada F, Pibarot P, Dumont É, Rodés-Cabau J. Myocardial injury after transaortic versus transapical transcatheter aortic valve replacement. Ann Thorac Surg 2015; 99(6): 20012009

38. Ribeiro HB, Nombela-Franco L, Muñoz-García AJ, Lemos PA, Amat-Santos I, Serra V, de Brito FS Jr, Abizaid A, Sarmento-Leite R, Puri R, Cheema AN, Ruel M, Nietlispach F, Maisano F, Moris C, Del Valle R, Urena M, Abdul Jawad Altisent O, Del Trigo M, Campelo-Parada F, Jimenez Quevedo P, Alonso-Briales JH, Gutiérrez H, García Del Blanco B, Perin MA, Siqueira D, Bernardi G, Dumont É, Côté M, Pibarot P, Rodés-Cabau J. Predictors and impact of myocardial injury after transcatheter aortic valve replacement: a multicenter registry. J Am Coll Cardiol 2015; 66 (19): 2075-2088

39. Elmariah S, Fearon WF, Inglessis I, Vlahakes GJ, Lindman BR, Alu MC, Crowley A, Kodali S, Leon MB, Svensson L, Pibarot P, Hahn RT, Thourani VH, Palacios IF, Miller DC, Douglas PS, Passeri JJ; PARTNER Trial Investigators and PARTNER Publications Office. Transapical transcatheter aortic valve replacement is associated with increased cardiac mortality in patients with left 
ventricular dysfunction: insights from the PARTNER I trial. JACC Cardiovasc Interv 2017; 10(23): 2414-2422

40. Modolo R, Chang CC, Abdelghani M, Kawashima H, Ono M, Tateishi H, Miyazaki Y, Pighi M, Wykrzykowska JJ, de Winter RJ, Ruck A, Chieffo A, van Mourik MS, Yamaji K, Richardt G, de Brito FS Jr, Lemos PA, Al-Kassou B, Piazza N, Tchetche D, Sinning JM, Abdel-Wahab M, Soliman O, Søndergaard L, Mylotte D, Onuma Y, Van Mieghem NM, Serruys PW. Quantitative assessment of acute regurgitation following TAVR: a multicenter pooled analysis of 2,258 valves. JACC Cardiovasc Interv 2020; 13 (11): 1303-1311

41. Rampat R, Khawaja MZ, Byrne J, MacCarthy P, Blackman DJ, Krishnamurthy A, Gunarathne A, Kovac J, Banning A, Kharbanda R, Firoozi S, Brecker S, Redwood S, Bapat V, Mullen M, Aggarwal S, Manoharan G, Spence MS, Khogali S, Dooley M, Cockburn J, de Belder A, Trivedi U, Hildick-Smith D. Transcatheter aortic valve replacement using the repositionable LOTUS valve: United Kingdom experience. JACC Cardiovasc Interv 2016; 9(4): 367-372

42. Kalra SS, Firoozi S, Yeh J, Blackman DJ, Rashid S, Davies S, Moat N, Dalby M, Kabir T, Khogali SS, Anderson RA, Groves PH, Mylotte D, Hildick-Smith D, Rampat R, Kovac J, Gunarathne A, Laborde JC, Brecker SJ. Initial experience of a secondgeneration self-expanding transcatheter aortic valve: the UK \& Ireland Evolut R Implanters' Registry. JACC Cardiovasc Interv 2017; 10(3): 276-282

43. Thiele H, Kurz T, Feistritzer HJ, Stachel G, Hartung P, Eitel I, Marquetand C, Nef H, Doerr O, Lauten A, Landmesser U, AbdelWahab M, Sandri M, Holzhey D, Borger M, Ince H, Öner A, Meyer-Saraei R, Wienbergen H, Fach A, Frey N, König IR, Vonthein R, Rückert Y, Funkat AK, de Waha-Thiele S, Desch S. Comparison of newer generation self-expandable vs. balloonexpandable valves in transcatheter aortic valve implantation: the randomized SOLVE-TAVI trial. Eur Heart J 2020; 41(20): 18901899

44. Poulin F, Carasso S, Horlick EM, Rakowski H, Lim KD, Finn H, Feindel CM, Greutmann M, Osten MD, Cusimano RJ, Woo A. Recovery of left ventricular mechanics after transcatheter aortic valve implantation: effects of baseline ventricular function and postprocedural aortic regurgitation. J Am Soc Echocardiogr 2014; 27(11): 1133-1142

45. Kodali SK, Williams MR, Smith CR, Svensson LG, Webb JG, Makkar RR, Fontana GP, Dewey TM, Thourani VH, Pichard AD, Fischbein M, Szeto WY, Lim S, Greason KL, Teirstein PS, Malaisrie SC, Douglas PS, Hahn RT, Whisenant B, Zajarias A, Wang D, Akin JJ, Anderson WN, Leon MB; the PARTNER Trial Investigators. Two-year outcomes after transcatheter or surgical aortic-valve replacement. N Engl J Med 2012; 366(18): 16861695

46. Yoshijima N, Yanagisawa R, Hase H, Tanaka M, Tsuruta H, Shimizu H, Fukuda K, Naganuma T, Mizutani K, Araki M, Tada N, Yamanaka F, Shirai S, Tabata M, Ueno H, Takagi K, Higashimori A, Watanabe Y, Yamamoto M, Hayashida K; the OCEAN-TAVI investigators. Update on the clinical impact of mild aortic regurgitation after transcatheter aortic valve implantation: insights from the Japanese multicenter OCEAN-TAVI registry. Catheter Cardiovasc Interv 2020; 95(1): 35-44

47. Greason KL, Lahr BD, Stulak JM, Cha YM, Rea RF, Schaff HV,
Dearani JA. Long-term mortality effect of early pacemaker implantation after surgical aortic valve replacement. Ann Thorac Surg 2017; 104(4): 1259-1264

48. Poels TT, Houthuizen P, Van Garsse LA, Soliman Hamad MA, Maessen JG, Prinzen FW, Van Straten AH. Frequency and prognosis of new bundle branch block induced by surgical aortic valve replacement. Eur J Cardiothorac Surg 2015; 47(2): e47-e53

49. Hwang YM, Kim J, Lee JH, Kim M, Hwang J, Kim JB, Jung SH, Choo SJ, Nam GB, Choi KJ, Chung CH, Lee JW, Kim YH. Conduction disturbance after isolated surgical aortic valve replacement in degenerative aortic stenosis. J Thorac Cardiovasc Surg 2017; 154(5): 1556-1565.e1

50. Romano MA, Koeckert M, Mumtaz MA, Slachman FN, Patel HJ, Chitwood WR Jr, Barnhart GR, Grossi EA; the TRANSFORM Trial Investigators. Permanent pacemaker implantation after rapid deployment aortic valve replacement. Ann Thorac Surg 2018; 106 (3): 685-690

51. Sohn SH, Jang MJ, Hwang HY, Kim KH. Rapid deployment or sutureless versus conventional bioprosthetic aortic valve replacement: a meta-analysis. J Thorac Cardiovasc Surg 2018; 155(6): 2402-2412.e5

52. Coti I, Schukro C, Drevinja F, Haberl T, Kaider A, Kocher A, Laufer G, Andreas M. Conduction disturbances following surgical aortic valve replacement with a rapid-deployment bioprosthesis. J Thorac Cardiovasc Surg 2020; [Epub ahead of print] doi: 10.1016/ j.jtcvs.2020.01.083

53. Lam KY, Akca F, Verberkmoes NJ, van Dijk C, Claessens A, Soliman Hamad MA, van Straten AHM. Conduction disorders and impact on survival after sutureless aortic valve replacement compared to conventional stented bioprostheses. Eur J Cardiothorac Surg 2019; 55(6): 1168-1173

54. Dizon JM, Nazif TM, Hess PL, Biviano A, Garan H, Douglas PS, Kapadia S, Babaliaros V, Herrmann HC, Szeto WY, Jilaihawi H, Fearon WF, Tuzcu EM, Pichard AD, Makkar R, Williams M, Hahn $\mathrm{RT}, \mathrm{Xu} \mathrm{K}$, Smith CR, Leon MB, Kodali SK; the PARTNER Publications Office. Chronic pacing and adverse outcomes after transcatheter aortic valve implantation. Heart 2015; 101(20): $1665-1671$

55. Klaeboe LG, Brekke PH, Lie ØH, Aaberge L, Haugaa KH, Edvardsen T. Classical mechanical dyssynchrony is rare in transcatheter aortic valve implantation-induced left bundle branch block. Eur Heart J Cardiovasc Imaging 2019; 20(3): 271-278

56. Calle S, Coeman M, Desmet K, De Backer T, De Buyzere M, De Pooter J, Timmermans F. Septal flash is a prevalent and early dyssynchrony marker in transcatheter aortic valve replacementinduced left bundle branch block. Int J Cardiovasc Imaging 2020; 36(6): 1041-1050

57. Klaeboe LG, Brekke PH, Aaberge L, Haugaa K, Edvardsen T. Impact of transcatheter aortic valve implantation on mechanical dispersion. Open Heart 2020; 7(1): e001199

58. Faroux L, Chen S, Muntané-Carol G, Regueiro A, Philippon F, Sondergaard L, Jørgensen TH, Lopez-Aguilera J, Kodali S, Leon M, Nazif T, Rodés-Cabau J. Clinical impact of conduction disturbances in transcatheter aortic valve replacement recipients: a systematic review and meta-analysis. Eur Heart J 2020; 41(29): 2771-2781

59. Jørgensen TH, De Backer O, Gerds TA, Bieliauskas G, Svendsen $\mathrm{JH}$, Søndergaard L. Mortality and heart failure hospitalization in 
patients with conduction abnormalities after transcatheter aortic valve replacement. JACC Cardiovasc Interv 2019; 12(1): 52-61

60. Muntané-Carol G, Guimaraes L, Ferreira-Neto AN, WintzerWehekind J, Junquera L, Del Val D, Faroux L, Philippon F, RodésCabau J. How does new-onset left bundle branch block affect the outcomes of transcatheter aortic valve repair? Expert Rev Med Devices 2019; 16(7): 589-602

61. Moriña-Vázquez P, Moraleda-Salas MT, Manovel-Sánchez AJ, Fernández-Gómez JM, Arce-Léon Á, Venegas-Gamero J, BarbaPichardo R. Early improvement of left ventricular ejection fraction by cardiac resynchronization through His bundle pacing in patients with heart failure. Europace 2020; 22(1): 125-132

62. Sharma PS, Subzposh FA, Ellenbogen KA, Vijayaraman P. Permanent His-bundle pacing in patients with prosthetic cardiac valves. Heart Rhythm 2017; 14(1): 59-64

63. De Pooter J, Gauthey A, Calle S, Noel A, Kefer J, Marchandise S, Coeman M, Philipsen T, Kayaert P, Gheeraert P, Jordaens L, Timmermans F, Van Heuverswyn F, Bordachar P, le Polain de Waroux JB. Feasibility of His-bundle pacing in patients with conduction disorders following transcatheter aortic valve replacement. J Cardiovasc Electrophysiol 2020; 31(4): 813-821

64. Vijayaraman P, Cano Ó, Koruth JS, Subzposh FA, Nanda S, Pugliese J, Ravi V, Naperkowski A, Sharma PS. His-Purkinje conduction system pacing following transcatheter aortic valve replacement: feasibility and safety. JACC Clin Electrophysiol 2020; 6(6): 649-657

65. Knöll R, Iaccarino G, Tarone G, Hilfiker-Kleiner D, Bauersachs J, Leite-Moreira AF, Sugden PH, Balligand JL. Towards a redefinition of 'cardiac hypertrophy' through a rational characterization of left ventricular phenotypes: a position paper of the Working Group 'Myocardial Function' of the ESC. Eur J Heart Fail 2011; 13 (8): 811-819

66. Olivetti G, Melissari M, Capasso JM, Anversa P. Cardiomyopathy of the aging human heart. Myocyte loss and reactive cellular hypertrophy. Circ Res 1991; 68(6): 1560-1568

67. van Straten AH, Soliman Hamad MA, Peels KC, van den Broek $\mathrm{KC}$, ter Woorst JF, Elenbaas TW, van Dantzig JM. Increased septum wall thickness in patients undergoing aortic valve replacement predicts worse late survival. Ann Thorac Surg 2012; 94(1): 66-71

68. Puls M, Beuthner BE, Topci R, Vogelgesang A, Bleckmann A, Sitte M, Lange T, Backhaus SJ, Schuster A, Seidler T, Kutschka I, Toischer K, Zeisberg EM, Jacobshagen C, Hasenfuß G. Impact of myocardial fibrosis on left ventricular remodelling, recovery, and outcome after transcatheter aortic valve implantation in different haemodynamic subtypes of severe aortic stenosis. Eur Heart J 2020; 41(20): 1903-1914

69. Weidemann F, Herrmann S, Störk S, Niemann M, Frantz S, Lange V, Beer M, Gattenlöhner S, Voelker W, Ertl G, Strotmann JM. Impact of myocardial fibrosis in patients with symptomatic severe aortic stenosis. Circulation 2009; 120(7): 577-584

70. Herrmann S, Fries B, Salinger T, Liu D, Hu K, Gensler D, Strotmann J, Christa M, Beer M, Gattenlöhner S, Störk S, Voelker W, Bening C, Lorenz K, Leyh R, Frantz S, Ertl G, Weidemann F, Nordbeck P. Myocardial fibrosis predicts 10-year survival in patients undergoing aortic valve replacement. Circ Cardiovasc Imaging 2018; 11(8): e007131
71. Hwang IC, Kim HK, Park JB, Park EA, Lee W, Lee SP, Kim YJ, Sohn DW, Oh JK. Aortic valve replacement-induced changes in native $\mathrm{T} 1$ are related to prognosis in severe aortic stenosis: $\mathrm{T} 1$ mapping cardiac magnetic resonance imaging study. Eur Heart J Cardiovasc Imaging 2020; 21(6): 653-663

72. Chin CW, Messika-Zeitoun D, Shah AS, Lefevre G, Bailleul S, Yeung EN, Koo M, Mirsadraee S, Mathieu T, Semple SI, Mills NL, Vahanian A, Newby DE, Dweck MR. A clinical risk score of myocardial fibrosis predicts adverse outcomes in aortic stenosis. Eur Heart J 2016; 37(8): 713-723

73. Kearney LG, Lu K, Ord M, Patel SK, Profitis K, Matalanis G, Burrell LM, Srivastava PM. Global longitudinal strain is a strong independent predictor of all-cause mortality in patients with aortic stenosis. Eur Heart J Cardiovasc Imaging 2012; 13(10): 827-833

74. Dulgheru R, Magne J, Davin L, Nchimi A, Oury C, Pierard LA, Lancellotti $P$. Left ventricular regional function and maximal exercise capacity in aortic stenosis. Eur Heart J Cardiovasc Imaging 2016; 17(2): 217-224

75. Levy-Neuman S, Meledin V, Gandelman G, Goland S, Zilberman L, Edri O, Shneider N, Abaeh N, Bdolah-Abram T, George J, Shimoni S. The association between longitudinal strain at rest and stress and outcome in asymptomatic patients with moderate and severe aortic stenosis. J Am Soc Echocardiogr 2019; 32(6): 722729

76. Zhu D, Ito S, Miranda WR, Nkomo VT, Pislaru SV, Villarraga HR, Pellikka PA, Crusan DJ, Oh JK. Left ventricular global longitudinal strain is associated with long-term outcomes in moderate aortic stenosis. Circ Cardiovasc Imaging 2020; 13(4): e009958

77. Eleid MF, Sorajja P, Michelena HI, Malouf JF, Scott CG, Pellikka PA. Flow-gradient patterns in severe aortic stenosis with preserved ejection fraction: clinical characteristics and predictors of survival. Circulation 2013; 128(16): 1781-1789

78. Zheng Q, Djohan AH, Lim E, Ding ZP, Ling LH, Shi L, Chan ES, Chin CWL. Effects of aortic valve replacement on severe aortic stenosis and preserved systolic function: systematic review and network meta-analysis. Sci Rep 2017; 7(1): 5092

79. Altes A, Ringle A, Bohbot Y, Bouchot O, Appert L, Guerbaai RA, Gun M, Ennezat PV, Tribouilloy C, Maréchaux S. Clinical significance of energy loss index in patients with low-gradient severe aortic stenosis and preserved ejection fraction. Eur Heart $\mathbf{J}$ Cardiovasc Imaging 2020; 21(6): 608-615

80. Hachicha Z, Dumesnil JG, Pibarot P. Usefulness of the valvuloarterial impedance to predict adverse outcome in asymptomatic aortic stenosis. J Am Coll Cardiol 2009; 54(11): 1003-1011

81. Hachicha Z, Dumesnil JG, Bogaty P, Pibarot P. Paradoxical lowflow, low-gradient severe aortic stenosis despite preserved ejection fraction is associated with higher afterload and reduced survival. Circulation 2007; 115(22): 2856-2864

82. Cramariuc D, Cioffi G, Rieck AE, Devereux RB, Staal EM, Ray S, Wachtell K, Gerdts E. Low-flow aortic stenosis in asymptomatic patients: valvular-arterial impedance and systolic function from the SEAS Substudy. JACC Cardiovasc Imaging 2009; 2(4): 390-399

83. Nuis RJ, Goudzwaard JA, de Ronde-Tillmans MJAG, Kroon H, Ooms JF, van Wiechen MP, Geleijnse ML, Zijlstra F, Daemen J, Van Mieghem NM, Mattace-Raso FUS, Lenzen MJ, de Jaegere PPT. Impact of valvulo-arterial impedance on long-term quality of life and exercise performance after transcatheter aortic valve 
replacement. Circ Cardiovasc Interv 2020; 13(1): e008372

84. Kang DH, Park SJ, Lee SA, Lee S, Kim DH, Kim HK, Yun SC, Hong GR, Song JM, Chung CH, Song JK, Lee JW, Park SW. Early surgery or conservative care for asymptomatic aortic stenosis. N Engl J Med 2020; 382(2): 111-119

85. Lancellotti P, Vannan MA. Timing of intervention in aortic stenosis. N Engl J Med 2020; 382(2): 191-193

86. Nadir MA, Wei L, Elder DH, Libianto R, Lim TK, Pauriah M, Pringle SD, Doney AD, Choy AM, Struthers AD, Lang CC. Impact of renin-angiotensin system blockade therapy on outcome in aortic stenosis. J Am Coll Cardiol 2011; 58(6): 570-576

87. Bull S, Loudon M, Francis JM, Joseph J, Gerry S, Karamitsos TD, Prendergast BD, Banning AP, Neubauer S, Myerson SG. A prospective, double-blind, randomized controlled trial of the angiotensin-converting enzyme inhibitor ramipril in aortic stenosis (RIAS trial). Eur Heart J Cardiovasc Imaging 2015; 16(8): 834841

88. Ding Q, Zhang Z, Liu H, Nie H, Berguson M, Goldhammer JE, Young N, Boyd D, Morris R, Sun J. Perioperative use of reninangiotensin system inhibitors and outcomes in patients undergoing cardiac surgery. Nat Commun 2019; 10(1): 4202

89. Dahl JS, Videbaek L, Poulsen MK, Pellikka PA, Veien K, Andersen LI, Haghfelt T, Møller JE. Effect of candesartan treatment on left ventricular remodeling after aortic valve replacement for aortic stenosis. Am J Cardiol 2010; 106(5): 713719

90. Benedetto U, Melina G, Refice S, di Bartolomeo R, Roscitano A, Angeloni E, Sinatra R. Dual renin-angiotensin system blockade for patients with prosthesis-patient mismatch. Ann Thorac Surg 2010; 90(6): 1899-1903

91. Goel SS, Aksoy O, Gupta S, Houghtaling PL, Tuzcu EM, Marwick T, Mihaljevic T, Svensson L, Blackstone EH, Griffin BP, Stewart WJ, Barzilai B, Menon V, Kapadia SR. Renin-angiotensin system blockade therapy after surgical aortic valve replacement for severe aortic stenosis: a cohort study. Ann Intern Med 2014; 161(10): 699-710

92. Magne J, Guinot B, Le Guyader A, Bégot E, Marsaud JP, Mohty $\mathrm{D}$, Aboyans V. Relation between renin-angiotensin system blockers and survival following isolated aortic valve replacement for aortic stenosis. Am J Cardiol 2018; 121(4): 455-460

93. Ochiai T, Saito S, Yamanaka F, Shishido K, Tanaka Y, Yamabe T, Shirai S, Tada N, Araki M, Naganuma T, Watanabe Y, Yamamoto M, Hayashida K. Renin-angiotensin system blockade therapy after transcatheter aortic valve implantation. Heart 2018; 104(8): 644651

94. Inohara T, Manandhar P, Kosinski AS, Matsouaka RA, Kohsaka S, Mentz RJ, Thourani VH, Carroll JD, Kirtane AJ, Bavaria JE, Cohen DJ, Kiefer TL, Gaca JG, Kapadia SR, Peterson ED, Vemulapalli S. Association of renin-angiotensin inhibitor treatment with mortality and heart failure readmission in patients with transcatheter aortic valve replacement. JAMA 2018; 320(21): 2231-2241

95. Rodriguez-Gabella T, Catalá P, Muñoz-García AJ, NombelaFranco L, Del Valle R, Gutiérrez E, Regueiro A, Jimenez-Diaz VA, Ribeiro HB, Rivero F, Fernandez-Diaz JA, Pibarot P, AlonsoBriales JH, Tirado-Conte G, Moris C, Diez Del Hoyo F, JiménezBritez G, Zaderenko N, Alfonso F, Gómez I, Carrasco-Moraleja M, Rodés-Cabau J, San Román Calvar JA, Amat-Santos IJ. Renin- angiotensin system inhibition following transcatheter aortic valve replacement. J Am Coll Cardiol 2019; 74(5): 631-641

96. Biviano AB, Nazif T, Dizon J, Garan H, Fleitman J, Hassan D, Kapadia S, Babaliaros V, Xu K, Parvataneni R, Rodes-Cabau J, Szeto WY, Fearon WF, Dvir D, Dewey T, Williams M, Mack MJ, Webb JG, Miller DC, Smith CR, Leon MB, Kodali S. Atrial fibrillation is associated with increased mortality in patients undergoing transcatheter aortic valve replacement: insights from the placement of aortic transcatheter valve (PARTNER) trial. Circ Cardiovasc Interv 2016; 9(1): e002766

97. Mentias A, Saad M, Girotra S, Desai M, Elbadawi A, Briasoulis A, Alvarez P, Alqasrawi M, Giudici M, Panaich S, Horwitz PA, Jneid H, Kapadia S, Vaughan Sarrazin M. Impact of pre-existing and new-onset atrial fibrillation on outcomes after transcatheter aortic valve replacement. JACC Cardiovasc Interv 2019; 12(21): 21192129

98. Gaudino M, Alessandrini F, Glieca F, Luciani N, Cellini C, Pragliola C, Morelli M, Canosa C, Nasso G, Possati G. Survival after aortic valve replacement for aortic stenosis: does left ventricular mass regression have a clinical correlate? Eur Heart J 2005; 26(1): 51-57

99. Westaby S, Jin XY, Katsumata T, Arifi A, Braidley P. Valve replacement with a stentless bioprosthesis: versatility of the porcine aortic root. J Thorac Cardiovasc Surg 1998; 116(3): 477-484

100. Imanaka K, Kohmoto O, Nishimura S, Yokote Y, Kyo S. Impact of postoperative blood pressure control on regression of left ventricular mass following valve replacement for aortic stenosis. Eur J Cardiothorac Surg 2005; 27(6): 994-999

101. Lindman BR, Goel K, Bermejo J, Beckman J, O’Leary J, Barker CM, Kaiser C, Cavalcante JL, Elmariah S, Huang J, Hickey GL, Adams DH, Popma JJ, Reardon MJ. Lower blood pressure after transcatheter or surgical aortic valve replacement is associated with increased mortality. J Am Heart Assoc 2019; 8(21): e014020

102. Mack MJ, Leon MB, Thourani VH, Makkar R, Kodali SK, Russo M, Kapadia SR, Malaisrie SC, Cohen DJ, Pibarot P, Leipsic J, Hahn RT, Blanke P, Williams MR, McCabe JM, Brown DL, Babaliaros V, Goldman S, Szeto WY, Genereux P, Pershad A, Pocock SJ, Alu MC, Webb JG, Smith CR; the PARTNER 3 Investigators. Transcatheter aortic-valve replacement with a balloon-expandable valve in low-risk patients. N Engl J Med 2019; 380(18): 1695-1705

103. Popma JJ, Deeb GM, Yakubov SJ, Mumtaz M, Gada H, O’Hair D, Bajwa T, Heiser JC, Merhi W, Kleiman NS, Askew J, Sorajja P, Rovin J, Chetcuti SJ, Adams DH, Teirstein PS, Zorn GL 3rd, Forrest JK, Tchétché D, Resar J, Walton A, Piazza N, Ramlawi B, Robinson N, Petrossian G, Gleason TG, Oh JK, Boulware MJ, Qiao H, Mugglin AS, Reardon MJ; the Evolut Low Risk Trial Investigators. Transcatheter aortic-valve replacement with a selfexpanding valve in low-risk patients. N Engl J Med 2019; 380(18): 1706-1715

104. Blackman DJ, Saraf S, MacCarthy PA, Myat A, Anderson SG, Malkin CJ, Cunnington MS, Somers K, Brennan P, Manoharan G, Parker J, Aldalati O, Brecker SJ, Dowling C, Hoole SP, Dorman S, Mullen M, Kennon S, Jerrum M, Chandrala P, Roberts DH, Tay J, Doshi SN, Ludman PF, Fairbairn TA, Crowe J, Levy RD, Banning AP, Ruparelia N, Spence MS, Hildick-Smith D. Long-term durability of transcatheter aortic valve prostheses. J Am Coll 
Cardiol 2019; 73(5): 537-545

105. Søndergaard L, Ihlemann N, Capodanno D, Jørgensen TH, Nissen H, Kjeldsen BJ, Chang Y, Steinbrüchel DA, Olsen PS, Petronio AS, Thyregod HGH. Durability of transcatheter and surgical bioprosthetic aortic valves in patients at lower surgical risk. J Am Coll Cardiol 2019; 73(5): 546-553

106. Ochiai T, Chakravarty T, Yoon SH, Kaewkes D, Flint N, Patel V, Mahani S, Tiwana R, Sekhon N, Nakamura M, Cheng W, Makkar R. Coronary access after TAVR. JACC Cardiovasc Interv 2020; 13 (6): 693-705

107. Buzzatti N, Romano V, De Backer O, Soendergaard L, Rosseel L, Maurovich-Horvat P, Karady J, Merkely B, Ruggeri S, Prendergast B, De Bonis M, Colombo A, Montorfano M, Latib A. Coronary access after repeated transcatheter aortic valve implantation: a glimpse into the future. JACC Cardiovasc Imaging 2020; 13(2 Pt 1): 508-515

108. Nai Fovino L, Scotti A, Massussi M, Cardaioli F, Rodinò G, Matsuda Y, Pavei A, Masiero G, Napodano M, Fraccaro C, Fabris $\mathrm{T}$, Tarantini G. Coronary angiography after transcatheter aortic valve replacement (TAVR) to evaluate the risk of coronary access impairment after TAVR-in-TAVR. J Am Heart Assoc 2020; 9(13): e016446

109. Nalluri N, Atti V, Munir AB, Karam B, Patel NJ, Kumar V, Vemula P, Edla S, Asti D, Paturu A, Gayam S, Spagnola J, Barsoum E, Maniatis GA, Tamburrino F, Kandov R, Lafferty J,
Kliger C. Valve in valve transcatheter aortic valve implantation (ViV-TAVI) versus redo-Surgical aortic valve replacement (redoSAVR): a systematic review and meta-analysis. J Interv Cardiol 2018; 31(5): 661-671

110. Fukuhara S, Brescia AA, Deeb GM. Surgical explantation of transcatheter aortic bioprostheses: an analysis from the Society of Thoracic Surgeons Database. Circulation 2020; 142(23): 22852287

111. D’Ascenzo F, Salizzoni S, Saglietto A, Cortese M, Latib A, Franzone A, Barbanti M, Nietlispach F, Holy EW, Burriesci G, De Paoli A, Fonio P, Atzeni F, Moretti C, Perl L, D'Amico M, Rinaldi $\mathrm{M}$, Conrotto F. Incidence, predictors and cerebrovascular consequences of leaflet thrombosis after transcatheter aortic valve implantation: a systematic review and meta-analysis. Eur J Cardiothorac Surg 2019; 56(3): 488-494

112. Rheude T, Pellegrini C, Stortecky S, Marwan M, Xhepa E, Ammon F, Pilgrim T, Mayr NP, Husser O, Achenbach S, Windecker S, Cassese S, Joner M. Meta-analysis of bioprosthetic valve thrombosis after transcatheter aortic valve implantation. Am J Cardiol 2021; 138: 92-99

113. Midha PA, Raghav V, Sharma R, Condado JF, Okafor IU, Rami T, Kumar G, Thourani VH, Jilaihawi H, Babaliaros V, Makkar RR, Yoganathan AP. The fluid mechanics of transcatheter heart valve leaflet thrombosis in the neosinus. Circulation 2017; 136(17): 1598-1609 